\title{
GIS planning, Web and 3D Web GIS applications for the man- agement and analysis of MV/LV electrical networks in the re- gion of Medjez el Bab (North-West of Tunisia)
}

\author{
Mohamed Hafedh Hamza 1, 2, Mohamed Chmit ${ }^{2}$ \\ Department of Geography and Geographic Information Systems, Faculty of Arts and Humanities, King \\ Abdulaziz University, Jeddah, KSA \\ 2 Geomatics Section, Department of Geology, Faculty of Science of Tunis, University of Tunis El Manar, \\ Tunisia \\ * Correspondence: author: Mohamed Hafedh Hamza, ORCID ID: https://orcid.org/0000-0001-8259-5586 \\ Email: mhhamza@kau.edu.sa / hafedh.hamza@fst.rnu.tn
}

\begin{abstract}
Electric energy has become essential nowadays not only for the daily life of each of us but also for the economy of different countries. Geographic Information Systems (GIS) have an essential part to play in the management and planning of electricity distribution in both conventional and smart networks. That is an important element of urban planning and needs to be well assessed in order to improve the level of decision making and investment benefits. Data management using GIS becomes essential when smart grid is applied over the electricity network and will facilitates communication between the managers and the consumers. Since the management of electricity network data was previously done in Tunisia based on paper maps and plans, the purpose of this study is to present a case of planning based on GIS, Web, and 3D Web GIS, which would have significant positive consequences on this sector from a technical and financial sides with an improvement in customer satisfaction and the creation of an intelligent electricity network which will be a real decision-making tool. This work draws up an inventory of the network MV (Medium Voltage)/LV (Low Voltage) of the region of Medjez El Bab (Governorate of Beja, North-West of Tunisia) which routes electricity to the different big centers of consumption with access to MV/LV subscribers. The analysis of vehicle transport and pedestrian accessibility between installations, and the generation of Origin-Destination cost matrix to calculate the average transport distances between the service points or different localities, were done. Moreover, the analysis of the network's impedance allowed carrying out different scenarios to optimize performance and obtain more realistic routes. The different analyses carried out will be crucial for the maintenance of the electrical network and also for urban planning. Some important thematic maps were produced as part of this project as the Slope map, the Land use map, the map of the MV voltage domains, the map of the MV/LV transformer stations power, etc. A three-dimensional virtual city has been developed to visualize the graphical and attribute data for the study area. A Web and 3D Web GIS applications that allows the publication of the interactive maps on the Web as well as the database information, have been developed to offer users the possibility of consulting the produced products by internet. Finally, a website related to the study was developed.
\end{abstract}

Keywords: MV/LV network; GIS planning; Spatial network analysis; 3D virtual city; Web and 3D Web GIS applications

\section{1-. Introduction}

The main objective of planning electricity distribution networks is to determine the necessary conditions from a topological, structural, and physical point of view [1]. This goal has become a major issue in recent years for distribution planning services due to the various changes occurring in the electricity sector [2], [3]. The construction of new electrical facilities as substations, transformer, and distribution lines, depends on the available 
areas in the study area [4]. Determining the geographical location of electrical installations and identifying the elements of the electrical network is one of the great challenges that arise in the planning of the distribution network.

The Geographic Information Systems (GIS) are computational tools that allow georeferenced databases to be associated with digital maps to facilitate visualization of the geographical characteristics of a study are [5]. The evolution of geographic information science owes much to developments in GIS and spatial data analysis [6], [7]. GIS help making the data analyses easier to handle and providing high capabilities of dealing with large spatial data [8]. GIS are composed by data analysis and optimization tools, to solve problems in various fields of engineering [9]. Nowadays, GIS is a technology used in several planning departments of electrical distribution in Tunisia. Effective deployment of GIS in power distribution would go long way in the power industry efficient and financially viable besides enhancing the consumer's satisfaction due to uninterrupted quality power supply [10]. GIS today represents a solid basis for spatial data analysis [11]. The spatial analysis tools available in the GIS have been used in various planning studies of the electricity distribution network around the world [12], [13], [14], [15].

In addition to the basic functionalities of GIS, the WebGIS technique often integrates additional functionality using data from different sources. WebGIS, a combination of Web and GIS, has become a growing discipline since its beginning in 1993. In 1993, Xerox Corporation's research center in Palo Alto (USA) developed a Web-based map viewer, marking the origin of Web GIS. This experiment made it possible to retrieve interactive information from the Web, rather than providing access to purely static files [16]. GIS became a key Internet application that allowed the public to take advantage of the benefits of the Web [17].

The data management of the electricity network was previously done in Tunisia in a classic way using paper maps and plans, the idea of this work was to create an intelligent electricity network, and thus allow to take well-appropriate decisions and advances [18]. It consists of carrying out GIS applications for the analysis and management of the MV/LV electricity network of the National Tunisian Electricity and Gas Company STEG in the region of Medjez El Bab located in the governorate of Beja (North-West of Tunisia) and to set up a Web GIS application relating to it. Electricity network is made up of pylons, transformer stations and power lines. MV lines are generally of the overhead type (sometimes underground near urban sites), among these MV lines there are by-passes that supply the LV substations serving to supply the low voltage customers of the network [19]. The steps followed consist of creating a very large-scale database to set up the MV/LV network, defining and correcting the topology rules (duplicates, inclusions, etc.), determining the spatial relationships between objects, display the two MV/LV databases at several scales, migrate the data to a single geodatabase using the same coordinate system and the same spatial domain, and finally to set up a Web and 3D Web GIS applications. The objective All this will guarantee future users online results with their expectations in terms of the use and management of electricity networks, and to give the possibility to access in an adapted and simple way to these technologies to a simple or expert user. All this will guarantee to the future users online results that will match their expectations in terms of use and management of electrical networks. Besides, it will give to a casual or an expert user the possibility to access these technologies in an adapted and simplified way.

This paper is structured in six sections: Research question and objectives, Study area; Planning of the electrical networks using GIS tools; Web and 3D Web GIS applications and website development; Results and discussion; and Conclusion.

\section{2-. Research question and objectives}

This study focuses on the use of GIS as a tool for managing electricity distribution. This will facilitates facilitate the use of electricity network data and the rapid resolution of technical problems with a double gain in time and material and will also facilitates make communication easier between the managers of this resource and the corresponding 
consumers. The planning of the distribution network is also an important element of urban planning and needs to be assessed comprehensively in order to improve the level of decision making and investment benefits as demonstrated in the study of Zheng et al. in China in 2012 [20].

Many other studies related to GIS-based electricity network management were established around the world as the study of Mentis et al. in Nigeria in 2015 [21], the study of Candelisea and Westacottc in the United Kingdom in 2017 [22], the study of Ashkezari et al. in Oman in 2018 [23], the study of Li et al. in Australia in 2020 [24] and the study of Taye et al. in Ethiopia in [25]. All these studies demonstrated the importance of GIS as a powerful Management tool for electrical networks.

In Tunisia, electricity network data management was previously done based on paper maps and plans. The objective of this study is to present a case of planning based on GIS. This study will prove to be fruitful for the national Tunisian company of electricity and gas STEG with the possibility of the analysis of the accessibility of vehicles and pedestrian technicians between the installations, also the generation of Origin-Destination eost matrix to calculate the distances transport averages between the service points and the different localities as well as the analysis of the network impedance which will allow different scenarios to be carried out to optimize performance and obtain more realistic routes. In Tunisia, electrical networks data management was previously based on paper maps and plans. The objective of the present study is to prove the importance of planning electrical networks using GIS. Hence, this planning type will be very useful for the national Tunisian company of electricity and gas STEG. It will give the possibility to analyze the accessibility of vehicles and pedestrian technicians between the electrical installations. It will also permit the generation of Origin-Destination cost matrix in order to calculate the average-transport distances between the service points and the different localities. Moreover, it will allow to analyze the network impedance which in itself will lead to different possible scenarios to optimize performance and obtain more realistic routes. These various analyzes will be crucial for the maintenance of the electricity network as well as for future urban planning. A three-dimensional representation of the city was developed to visualize the graphical and attribute data of the study area. Web GIS and 3D Web applications allowing the publication of interactive maps on the Web as well as the information of the database, will be developed in this study to offer users the possibility of consulting the resulting products on the Internet. In addition, a website gathering the results of the study will be developed.

\section{3-. Study area}

The study area (Fig. 1) is located in the Northwest of Tunisia in the eastern part of the governorate of Beja. It lies between $36^{\circ} 45^{\prime} / 36^{\circ} 33^{\prime}$ North and $9^{\circ} 23^{\prime} / 9^{\circ} 45^{\prime}$ East. Its total area is $634 \mathrm{~km}^{2}$. The vegetation cover is generally much degraded on the mountains where the foothills are cleared. The mountains are therefore areas of concentration of water with a strong or medium erosive potential, while the foothills are little or moderately eroded because of their very low slope.

\section{4-. Planning of the electrical networks using GIS tools}

The first step is to process the cadastral data covering the city of Medjez El Bab and integrate them into a spatial database at a municipal level. The second one consists of processing physical data around the city of Medjez El Bab (Grand Medjez El Bab area) to create another spatial database at the local scale, to be able to implement afterwards the two geodatabases, at different scales and uses. The completion of that part of the study is articulated in the following phases: data acquisition, database design, the establishment of some important thematic maps and the elaboration of a 3D virtual city.

\section{4-1-. Data acquisition}


Nine official topographic maps produced by the national office of topography and cadaster OTC between 1982 and 1988 at a scale of 1: 25000 [26] were georeferenced and digitized using ArcGIS Desktop, topology rules were used to minimize digitizing errors. Ten topographic plans at a scale of 1:1000 produced at AutoCAD dwg format were also used [27]. These plans were processed: manual and automatic topological corrections were made on them. They were after that converted into feature class format and transferred into a Geodatabase in ArcGIS Desktop. Maxar 2020 background image related to our study area with a 0.5 meter resolution was extracted from the "World Imagery" service of "ArcGIS online" and was used to update data related to topographic maps and plans data. Maxar is a product of DigitalGlobe, an industry leader in satellite imagery and geospatial intelligence [28]. Moreover, a GPS Leica GS08plus was used in moving mode with centimetric accuracy (Horizontal: 1 centimeter, Vertical: 2 centimeters) for the purpose of updating the electrical network. The different steps of data acquisition are presented in Figure 2. We can also see in Figure 3 at different scales the obtained cartographic results. These results seem to be good: we can see for example in part D the position of MV electrical network with high geometric accuracy.

The final phase of the process was instantiating the data in the multi-representation Geodatabase. It was necessary to do a cartographic generalization to simplify the geographic data so that they are readable at the desired scale representation.

\section{4-2. Database design}

The database design was accomplished through MERISE methodology. MERISE is an Information System Design and Development methodology first introduced in the early 1980s, it was widely used in France [29]. MERISE proceeds to separate treatment of data and processes, where the data-oriented view is modeled in three stages, from conceptual, logical through to physical [30].

A Conceptual Data Model (CDM) helps to analyze the conceptual structure of an information system, to identify the principal entities to be represented, their attributes, and the relationships between them [31]. The conceptual data model consists of tables, each of which must include a field that uniquely identifies each record (primary keys). The choice of tables was made in our study at two regional levels: a first level relating to the delegation (Grand Medjez El Bab which represents the entire project area) and a second level relating to the municipality of Medjez El Bab.

To materialize the conceptual diagram "DB Designer" was used, it is a visual database design system that integrates database design, modeling, creation, and maintenance into a single, seamless environment. The transit from Conceptual Data Model CDM to Physical Data Model PDM was done using ArcGIS Diagrammer which is a productivity tool for GIS professionals to create, edit or analyze geodatabase schema. Schema is presented as editable graphics in an environment familiar to users of Microsoft Visual Studio. Essentially ArcGIS Diagrammer is a visual editor for Esri's xml workspace documents that can be created in ArcMap or ArcCatalog [32]. The details of the operation are presented in Fig. 4. The Architecture and structural detail of the GeoDatabase are shown in Figure 5.

The next phase of the process was the structuring of the data in a multi-representation GeoDatabase. In this phase it is necessary to proceed to a cartographic generalization. Cartographic generalization is the process of controlling the amount of detailed information portrayed in a map. This also includes using the appropriate scale, purpose, and medium of the map. This form of Generalization commonly consists of reducing the visual detail of data by reducing the map scale when the map purpose suggests the need for a simpler design. As analytical approaches to geography arose in the 1950s and 1960s, generalization, especially line simplification and raster smoothing, was a target of study [33], [34]. Generalization of maps has become necessary due to automatic production of maps on the web, and the increased amount of detailed GIS data available [35]. A multirepresentation of the multiple Geodatabase at different scales is shown in Fig. 6. 
The last step was to determine the spatial relationships between features. Relationship classes in the geodatabase manage the associations between objects in one class (feature class or table) and objects in another. Objects at either end of the relationship can be features with geometry or records in a table.

\section{4-3-. Elaboration of thematic maps}

After data extraction and topological corrections, many thematic maps were established.

The DEM map was extracted using the Topo to Raster tool included in the Spatial Analyst extension of ArcGIS Desktop 10. The Topo to Raster tool is an interpolation method specifically designed for the creation of hydrologically correct digital elevation models-, it is based on the ANUDEM program developed by Michael Hutchinson [36], [37]. The DEM map showed that the plains and hills represent the dominant topographic aspect in the area (nearly 75\%). The Slope map extracted using the Slope tool of Spatial Analyst (Fig. 7) showed that $62 \%$ of the study area is with a slope less than $6 \%, 28 \%$ of the land has slopes between 6 to $18 \%, 5 \%$ has relatively steep slopes of 18 to $30 \%$ and about $5 \%$ of the land has steep slopes greater than $30 \%$. It follows that about $10 \%$ of the total study area has a slope greater than $18 \%$, representing lands threatened by moderate to severe erosion. The steeply sloping areas are located in the transition zones between reliefs and plains and are occupied by flourishing agriculture. These areas can however be the site of severe erosion even with relatively low slopes. This erosion is accentuated by torrential runoff in autumn and winter which can together directly cause flooding and stripping of the fertile cover of the plains surrounding the landforms.

An updated land use map was extracted based on the different topographic maps and plans, the Maxar 2020 image and GPS data (Fig. 8).

Many other maps related to the MV/LV electrical networks were established as the classification map of the MV electrical network, the map of the MV voltage domains and the map of MV/LV transformer stations power (Fig. 9).

\section{4-4-. Elaboration of a 3D virtual city}

$3 \mathrm{D}$ city model is a digital representation of the Earth's surface and its related objects such as Building, Tree, Vegetation, and some manmade feature belonging to urban area [38]. This realistic visualization represented in our study is a prototype that can help decision makers in future projects. Future projects may relate to the siting of works or other electrical network extensions while taking into account what has been done. In order to allow different levels of modeling, several levels of details (LOD) have been defined : LOD 0 (Regional model): this is a digital terrain model (2.5D) showing the whole of a landscape and whose data comes mainly from airborne laser; LOD 1 (Urban model): "block model" in which the buildings are schematized in the form of blocks without roof structures, thus giving an idea of the distribution of the height of the buildings; LOD 2 (Urban model): same as above but with textures for facades and roofs (oblique photogrammetry); LOD 3 (Urban model): same model as above but with a more detailed architectural level; LOD 4 (Interior model): truly architectural "walkable" model, that is to say with a model of the interior of buildings [39].

The CityGML standard was used in our study. It is an XML-based encoding for 3D representation, allowing the sharing and storing of virtual models of cities and landscapes. It is executed as an open data model deployed as an application schema for Geography Markup Language 3, the extensible international standard for spatial data exchange released by the Open Geospatial Consortium (OGC). CityGML offers a standard model to describe 3D objects in terms of their geometry, topology, semantics and appearance. It also contains generalization hierarchies between classes, aggregations, relationships between objects and spatial properties [40], [41]. ArcSecene and SketchUp were used in that part of the study. ArcScence, one of the ArcGIS Desktop applications, is a 3D visualization application that allows to view GIS data in three dimensions. ArcScene permits also to 
make 3D animations. SketchUp is a 3D modeling computer program for a wide range of drawing applications such as architectural, interior design, landscape architecture, civil and mechanical engineering, film and video game design.

Under ArcScene, we first proceeded to model the geographic space which is delimiting a region of $10 \mathrm{~km}$ around the city of Medjez El Bab. The first step is to display the digital terrain model in a 3D planimetric view, using the 3D Analyst extension; we were able to create other cartographic models superimposed with the digital terrain model. Using Sketch Up software, we modeled the various elements that make up the MV / LV networks based on the drawing commands (geometry, coloring, and modification) and photos taken in the field.

The modeling of the land use components of our study area consists in adding the different data layers (urban, roads, hydrography and electrical network) in the scene and superimpose them with the relief and then performing an extrusion of the buildings to create realistic 3D objects (extrude according to the heights and the number of floors). The 3D model of the study area obtained (Fig. 10) will then be used as a model for performing the video simulation in ArcScence.

\section{5-. Web and 3D Web GIS applications and Website development}

\section{5-1-. Web GIS application}

This phase is related to the realization of a Web GIS in order to offer users the possibility of consulting the produced products by internet.

The world had 4.79 billion Internet users in 2020, or 5.5\% more than in 2019 . This is $166 \%$ more than 10 years ago [42]. The Internet, and in particular the World Wide Web, enables easy access to spatial data and applications that can offer fast and simple solutions to the spatial needs of people, public services and business operations [43]. Web GIS is relatively recent but very fast-growing sub-set of Geographic Information System. It is getting particular significance for spatial data handling over the web [44]. It is becoming more and more used in various fields such as planning, natural resource management, environment, market research, logistics, and others. The web is the most commonly used Internet technology and Web GIS is the most common form of online GIS [45]. The Web GIS consists in using the Internet browser as a standard interface to access a number of mapping services or applications to display and interact with data. The solutions generated by these services are generally proposed in the literature according to the different levels of interactivity resulting from the functionalities offered to the user to act on the map. Web GIS can be defined as any GIS that uses web technology to communicate between a server and a client [46]. Web-based GIS applications have gained popularity due to their ease of use and simplicity [47]. Web GIS have introduced and demonstrated many advantages over traditional GIS, such as their global reach, huge user base, low cost, ease of sharing and use in different fields as disaster recovery, telecommunication services, real estate business, accident analysis, tourism, etc. [48]

In the framework of our study related to electricity network, the client side is a spatial data visualization interface (Map Viewer) based on GeoExt. The latter is a web application developed under OpenLayers to create and publish maps. This interface allows adding WMS (Web Map Service) layers from GeoServer and from an API (Application Programming Interface) such as Google Maps (Fig. 11).

Following software tools were used in our study: GeoServer, OpenLayers, GeoExt and HTML.

Data implementation is based on setting up and structuring the data in GeoServer, then symbolizing layers in AltlasStyler and developing the cartographic interface in GeoExt.

In our project, we have realized two cartographic interfaces: One for a global visualization of data using the database of the Greater Medjez El Bab (where the MV network is 
located) (Fig. 12), a second one to display the municipal data (where the LV network is located) (Fig. 13).

\section{5-2-. 3D Web GIS}

3D Web GIS has become a real requirement in several fields of study thanks to its devices for analyzing 3D models linked to spatially referenced data [49]. The main purpose of Web GIS is to help users to conveniently access, display and analyse spatial information incorporated in existing data sources [50]. Web-based GIS sites should be based on three main components: user-friendliness, data accuracy and interoperability [51].

It is important to note that standardization initiatives over the last decade have facilitated the implementation of 3D Web GIS. Indeed, since 2010, two standardization proposals have been published as OGC discussion paper: the Web Visualization Service (WVS) [52] using server-side rendering; and the 3D Web Service (W3DS) [53] providing 3D data for client-side rendering. WVS and W3DS have been included in the OGC-approved 3D Portrayal Service Standard 1.0 [54] enabling an interoperable presentation of 3D content-based services with a good overview of 3D representation, geometric and topological data models, database models, formats and applications [55], [56].

Thanks to the Google Earth plug-in and the JavaScript API, we were able to integrate the specificities of Google Earth and its 3D renderings into web pages. In fact, we used the API to create points and lines, project images on a relief, add 3D models or import KML files, and we also developed advanced 3D mapping applications. The client side is a spatial data visualization interface based on Ext.ux.GEarth code. This interface allows adding KML layers from Google Earth Community and an API as Google Maps.

After modeling the "3D virtual city" data in ArcScene for a later storage in the server, KML files were created in Google Earth by adding the feature classes previously modeled in ArcScene using the Layer to KML tool. Using Google Earth, we modeled the KML data into 3D according to the graphic symbols exported by ArcScene or SketchUp. The data layers were then organized in a directory to update the relative information in order to obtain a 3D virtual model. To put the resulting file on the server, we just shared and send the content to Google Earth Community in order to obtain a network link to our model.

The map interface is realized using the Google Earth API. After exporting the data to Google Earth Community (Online Map Server) and writing the Java Script file using the KML network link, the web map interface is created where the map background and the different layers can be visualized. From this interface you can activate or deactivate the layers, view or un-view the legend, zoom in or out. We are also able to move through the layers, change the scale, identify the different types of layers, print and display the ruler (Fig. 14).

This interface offers a variety of dynamic mapping features from the side toolbar, including : Display the different map layers, Add KML/KMZ layers, Search for a location, Display the status bar (coordinates, elevation, etc.), Display different options (grid, planisphere map, scale, atmosphere), Enable or disable navigation (Mouse), Zoom control (Zoom in and Zoom off), Display information related to selected objects (attributes), Display Google Earth layers (Borders, Roads, 3D Buildings, Relief, etc.) and add sunlight and view the map in real time (Fig. 15).

\section{5-3-. Website development}

The structuring of the website consists in building the global architecture of the website by organizing the different information. The first step was to make an inventory of the contents of the website and to group them by theme in order to constitute headings (rubricing). Our website was structured as shown in Fig. 16. The used editor was WordPress, and WampServer as a web development platform (comprising Apache and MySQL servers). The programming languages were CSS, PHP, XML and JavaScript.

The produced website included multiple interfaces: a Home Welcome window where the slider, the presentation of the project and the different organizations involved 
in the project are displayed; an "Introduction" window which presents the scope of the study and a general idea about the city of Medjez El Bab; a window named "Thematics" on which there is a presentation of Geomatics, GIS, used tools, and details of the eclectic network; a "Results and Analysis" window which presents to the user the results of thematic data, spatial analysis, network analysis scenarios and the 3D modeling; a "Media Library" window where the user can view photos (city photos, photo gallery taken in the field), videos, maps and articles; an "Interactive applications" window. From that window, three interactive applications can be displayed: "Grand Medjez El Bab area", "Municipality of Medjez El Bab area" and "3D virtual city" (Fig. 17); "About" window with general information and finally "Contact" window with location map and phone and email contacts.

\section{6-. Results and discussion}

The geometric accuracy in such studies is very important and depends on the accuracy of the used data. In our study we used Topographic maps 1: 25000 dating from 1982 and 1988 and AutoCAD plans 1:1000 dating from 2006. As the data generated from these maps and plans are not up to date, we were obliged to update it. We relied in our case on a free Maxar 2020 imagery with a 0.5 meter resolution. Moreover, we established a GPS campaign to accurately map the components of the electricity network: a GPS Leica GS08plus was used in moving mode with centimetric accuracy (Horizontal: 1 centimeter, Vertical: 2 centimeters) for that purpose. In figure 3 we can see at different scales the obtained cartographic results and we can see in part D of the same figure that the accuracy of the results seems to be good: we can see the position of MV electrical network (presented as a blue line) with high geometric accuracy (this electrical network is located in the right side of the road RN6 in that case).

The establishment of GIS-planning in the management of electrical networks depends clearly on the availability and the accuracy of cartographic data which are not always available, especially in developing countries. Establishing GPS campaigns for network mapping can be a very important tool in such studies, especially with high accuracy GPS receivers. In addition, free high-resolution satellite images are increasingly available nowadays. Using these images in similar studies will update the mapping data and extract a fairly complete database of the electrical networks.

Many Spatial and Network analyses were established in the study area using ArcGIS extensions Spatial Analyst and Network Analyst. Spatial Analyst was used in terrain modelling as the extraction of DEM and Slope maps, and for spatial analysis, while Network Analyst enabled an efficient organization and coordination of vehicles and intelligent analysis of the transport network. This extension enabled the right decisions to be made by developing strategic routing plans.

We have extracted in our study area the corresponding Slope map. That map showed that $62 \%$ of the study area is with low slopes, $28 \%$ with medium slopes, $5 \%$ with relatively steep slopes and about $5 \%$ of the land has high steep slopes. We were based on this map to analyze the STEG technician's pedestrian accessibility. International standards say that the average speed of walking is between 3.2 and $5.2 \mathrm{~km} / \mathrm{h}$ on a flat ground and that average varies according to the slope direction and value [57]. The analysis was based on making an intersection between the slope map and the electrical network. The extracted slope values were then introduced into Network Analyst thus allowing to check the variation of the speed and the time taken as a function of slope value and direction, knowing that the slope classes considered were: 0 to $5 \% ; 5$ to $8 \% ; 8$ to $12 \%$ and more than $12 \%$. The different steps of that analysis is shown in Figure 18. We had also established two topographic profiles showing the importance of topographic roughness in pedestrian accessibility. The profiles extracted were integrated into Network Analyst to check the effects of slope on speed and travel time: Example 1: Distance $=2.2 \mathrm{~km}$, time $=36 \mathrm{~min}$, average speed $=3.66 \mathrm{~km} / \mathrm{h}$; Example 2: Distance $=2.2 \mathrm{~km}$, time $=22 \mathrm{~min}$, average speed $=6 \mathrm{~km} / \mathrm{h}$. The obtained results seem to be logical, in fact the speed in example 1 (route with rugged 
topography) is lower than the speed in example 2 (route with less rugged topography); it shows that the slope of the path influences the speed (Fig. 19).

For the study of accessibility using vehicle transport, seven categories of roads with different reference speeds have been considered: Motorways, Motorway junction, Primary roads (National roads), Collector roads, Secondary roads (Local roads), Tertiary roads (Unclassified roads), Quaternary roads (Agricultural tracks) with the following respective maximum speeds: 100, 60, 80, 70, 60, 40 and $30 \mathrm{~km} / \mathrm{h}$. The analysis on Network Analyst is carried out on the transport network using several criteria: speed, time, and hierarchy. Many network analyses were established in our study as the determination of the shortest path between one of the MV / LV transformer stations and the source station located in the region of "Oued Zarga". In this case the length of the shortest path is 19.2 $\mathrm{km}$ with a travel time of 24 minutes (Fig. 20). Assuming for example that the RN5 road is cut due to road works, the shortest path extracted will be different with a length of 25.5 and a travel time of 18 minutes. The route is shorter in the second scenario, and this can be explained by different factors such as the speed limit in the type of path crossed which differs from one type of path to another. Some other analysis of calculation of routes according to a chosen impedance (best route with distance impedance, best route with time impedance) were also established.

An Origin Destination Cost Matrix was also calculated in Network Analyst to calculate average transport distances between the service points on the different localities (cities, villages) and the MV / LV transformer stations. The same analysis was done using time impedance. The following data was considered to calculate the transport cost: STEG vehicle: Isuzu D-max Diesel, Average consumption: 8.2 liters/100 km, Diesel price: 1.605 Dinars/liter.

The calculation of service areas was also established. A network service area is a region that encompasses all accessible routes (that is, streets that are within specified impedance). We have extracted service areas in the city of Medjez El Bab indicating path accessibility according to time at 5, 10, 15, 20 and 30 minutes (Fig. 21). This has enabled for example, to organize service missions according to their duration.

All the last results will be crucial in the case of a power failure or in the case of maintenance work and can also be used in a future urban planning as demonstrated in the study of Zheng et al. in China in 2012 [20]. Similar procedures will produce time, material and organizational gains compared to conventional ones.

A three-dimensional representation of the study area as well as the electrical networks was also carried out, giving a realistic visualization of our study area, which can be considered as a prototype that can help decision-makers of the STEG in their future projects. Web GIS and 3D Web GIS demonstrated many advantages over traditional GIS, enabling the possibility of consulting cartographic products via the Internet, that's why the developed Geodatabase was ultimately used to set up a Web GIS and 3D Web GIS application and a Website with multiple interfaces and that can be used to include thematic data, spatial analysis, network analysis scenarios, 3D modeling and many others Interactive applications in the study area. With the developed website, we were also able to link Google Maps and the photos of the power poles with an explanatory video sequence to gather as much information as possible about the electricity network. Moreover, on the interactive windows of the website, it was possible to set up a display at different scales.

\section{7-. Conclusion}

Before this work was carried out, the monitoring of the electricity network of the region of Medjez El Bab was based on paper cartographic documents, without any recourse to GIS. In this paper we discussed the contribution of GIS in the field of planning of the electric networks with the aim to improve the capacities and the output of the national company of electricity and gas in Tunisia (STEG). A complete database related to the study area gathering all the useful data was created. Different topographic maps and plans related to the study area were used as 1: 25000 topographic maps, 1: 5000 plans as 
well as Maxar background image with a 0.5-meter resolution, extracted from the "World Imagery" service of "ArcGIS online". That image was used to update data related to topographic maps and plans. GPS centimetric data was used to update electrical networks. We then carried out the processing of these data to produce many thematic maps such as DEM map and slope map. The design of the multiple Geodatabase in order to obtain a geographic database with multiple representations, including spatial relationships, was carried out. Using the ArcGIS Network Analyst tool, an interpretation of the slope map and the MV/LV network maps was carried out with the realization of scenarios according to the transport network (roads and pedestrian paths). Different categories of roads were considered in the analysis of the transport network using the following criteria: speed, time and hierarchy. The objective was the analysis of the shortest path, the calculation of routes according to a chosen impedance (best route with distance impedance, best route with time impedance), the generation of the origin-destination cost matrix to calculate the average transport distances between the service points or different localities (towns, villages) and the MV/LV transformer stations. We also did the same type of analysis using the temporal impedance and obtained a table of combinations for each matrix. The calculation of the service areas related to the accessibility of the paths according to different times was also established to organize service missions. Obviously, the accessibility of each category of the network depends on the percentage of the slope. To confirm this, we compared for some topographic profiles the distance and time needed to reach the electrical stations, the results showed that the steeper the slope, the lower the speed and the longer the time, which is quite logical.

The development of a 3D virtual city gave us a realistic visualization for our study area, which can be considered as a prototype that can help decision-makers in their future projects. Future projects may involve the implementation of further extensions to the electrical network while considering what has been done. The established Web GIS application offers users the possibility to consult the made products by internet. The client side is a spatial data visualization interface (Map Viewer) based on GeoExt. This interface allows adding WMS layers from GeoServer and an API such as Google Maps. In our study, we were able to integrate Google Earth and its 3D rendering into the web pages thanks to the Google Earth plug-in and the JavaScript API. We were able to create points and lines, to do projection of images, to add 3D models and to import of KML files. We have also been able to develop advanced 3D mapping applications. The client side is a spatial data visualization interface based on the Ext.ux.GEarth code. This interface allows us to add KML layers from the Google Earth community and from an API such as Google Maps. Through the elaborated website we were also able to create a link between Google Maps and the photos of the power poles with an explanatory video sequence to collect the maximum of information about the electrical network. On the interactive windows of the website, it is possible to establish a display of different scales: a display at the level of the delegation with a scale of 1:25000 and a display at the level of the municipality with a scale of 1:5000.

This work opens wide perspectives; in fact, it would be possible to reproduce similar work established in that pilot zone in other zones related to the national Tunisian electricity and gas company STEG across the country. This will help decision makers to better manage electrical networks in the future. 




Figure 1. Study area. 


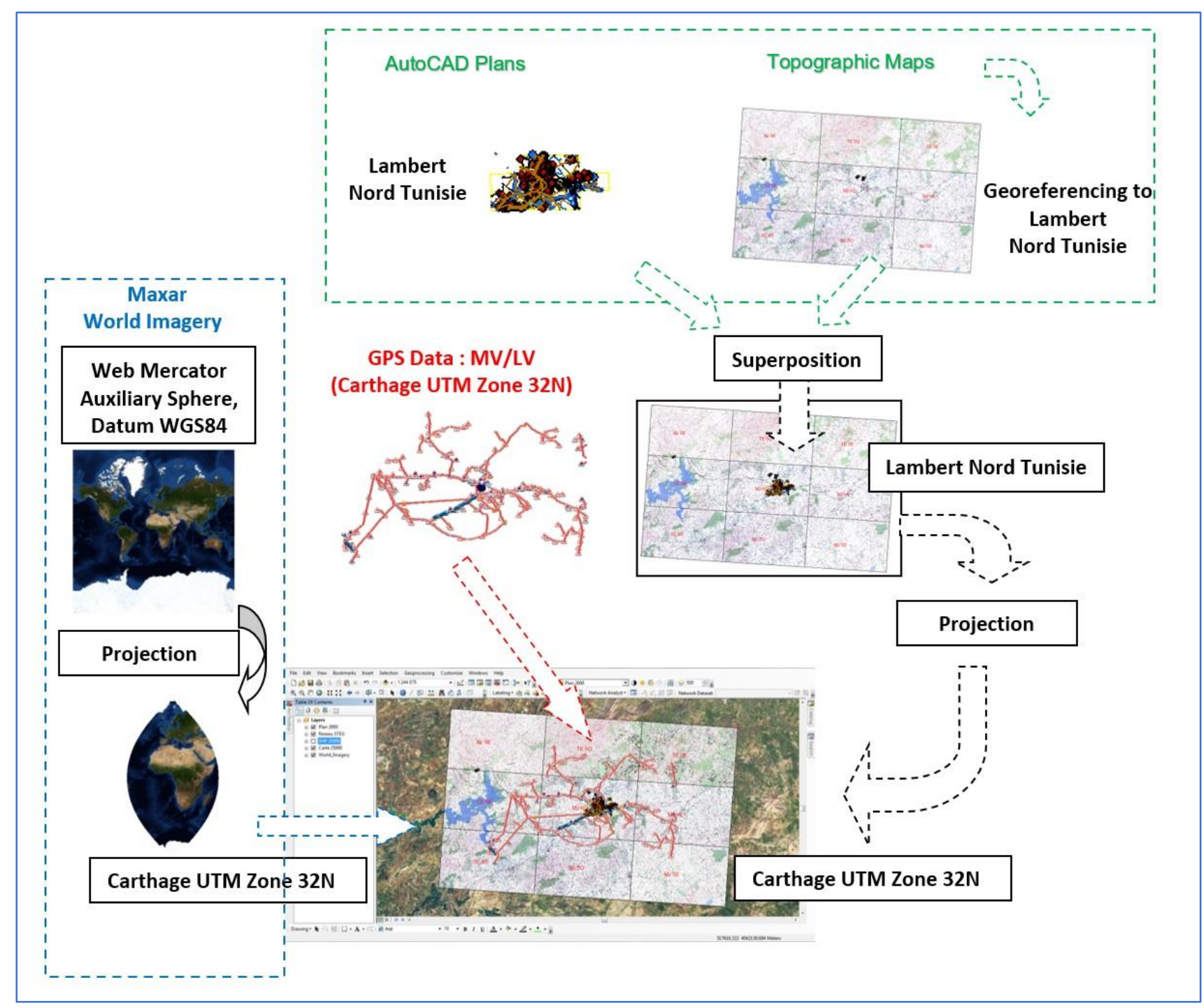

Figure 2. Steps followed for the data acquisition. 




Figure 3. Presentation at different scales of MV/LV electrical networks. 


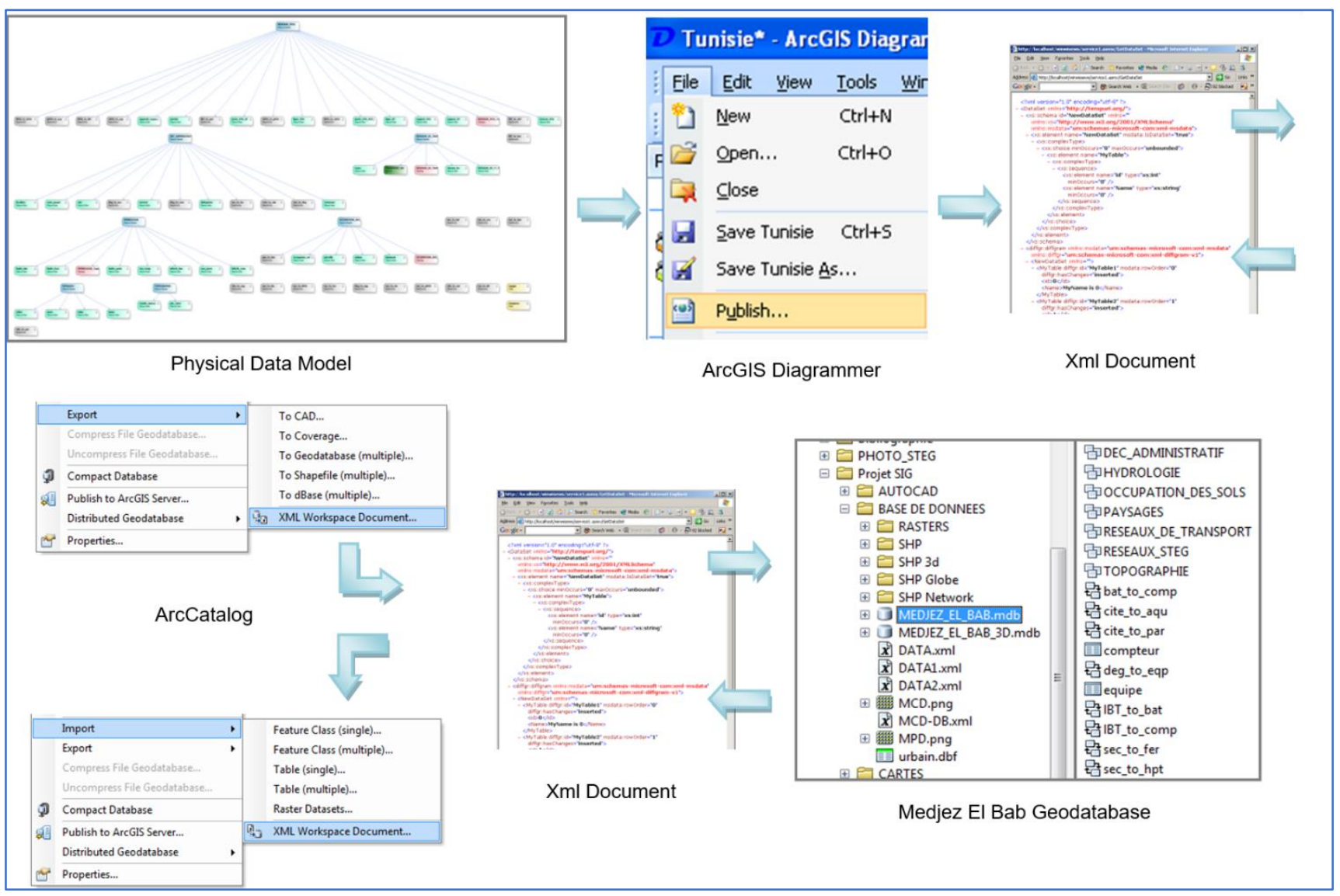

Figure 4. Switch from ArcGis Diagrammer to Arccatalog

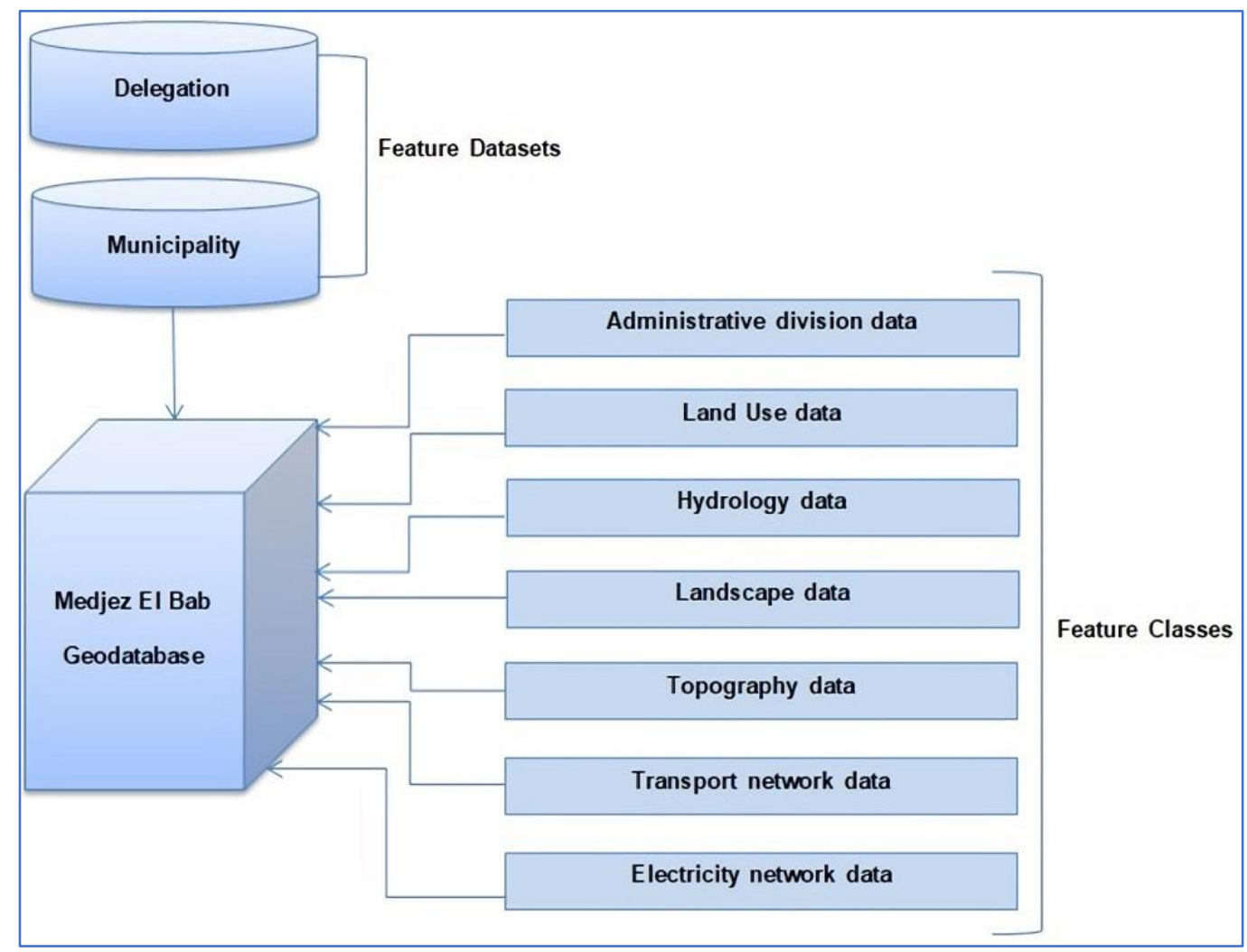

Figure 5. GeoDatabase architecture and its structural detail. 


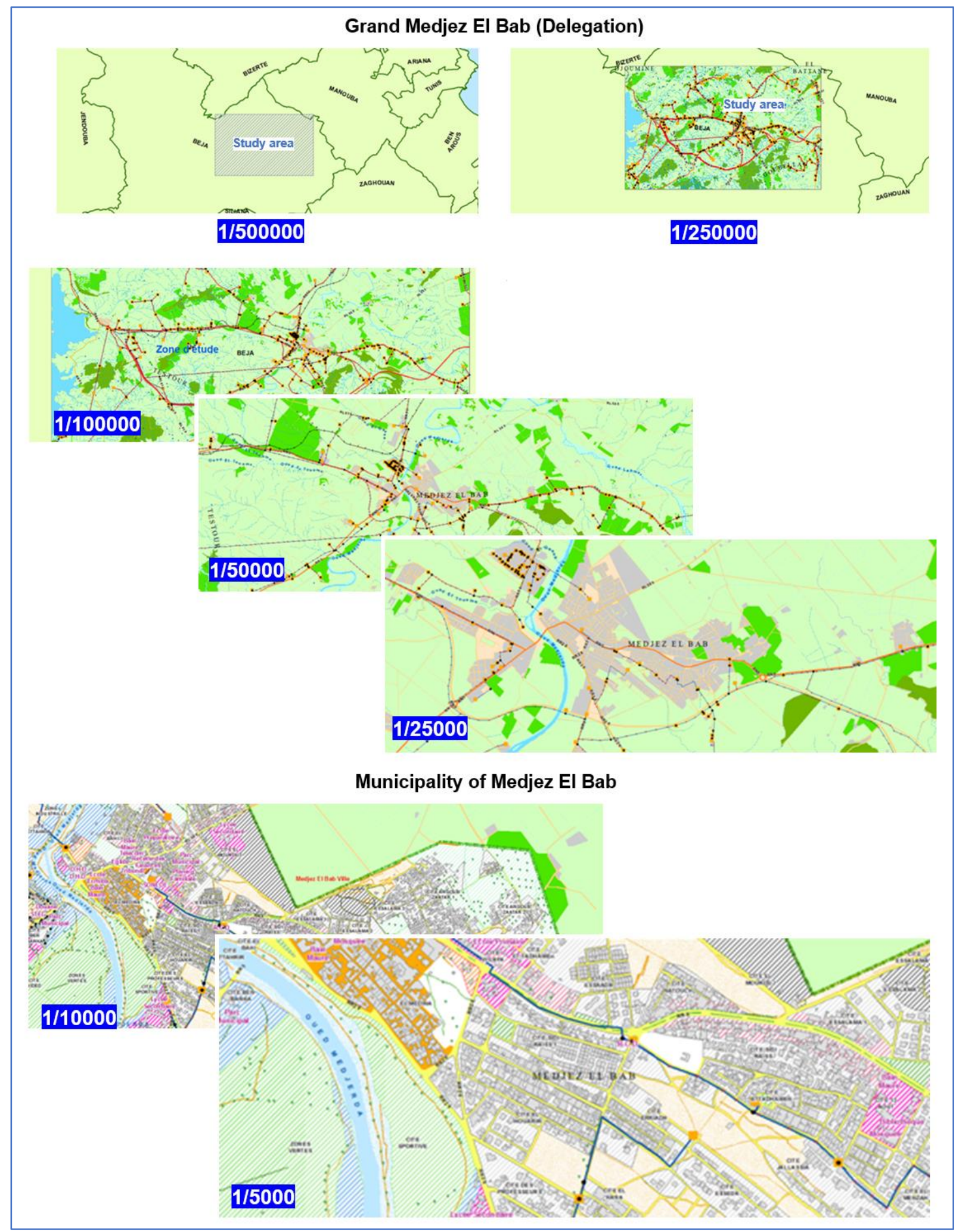

Figure 6. Multi-representation schema of the multiple Geodatabase at different scales. 


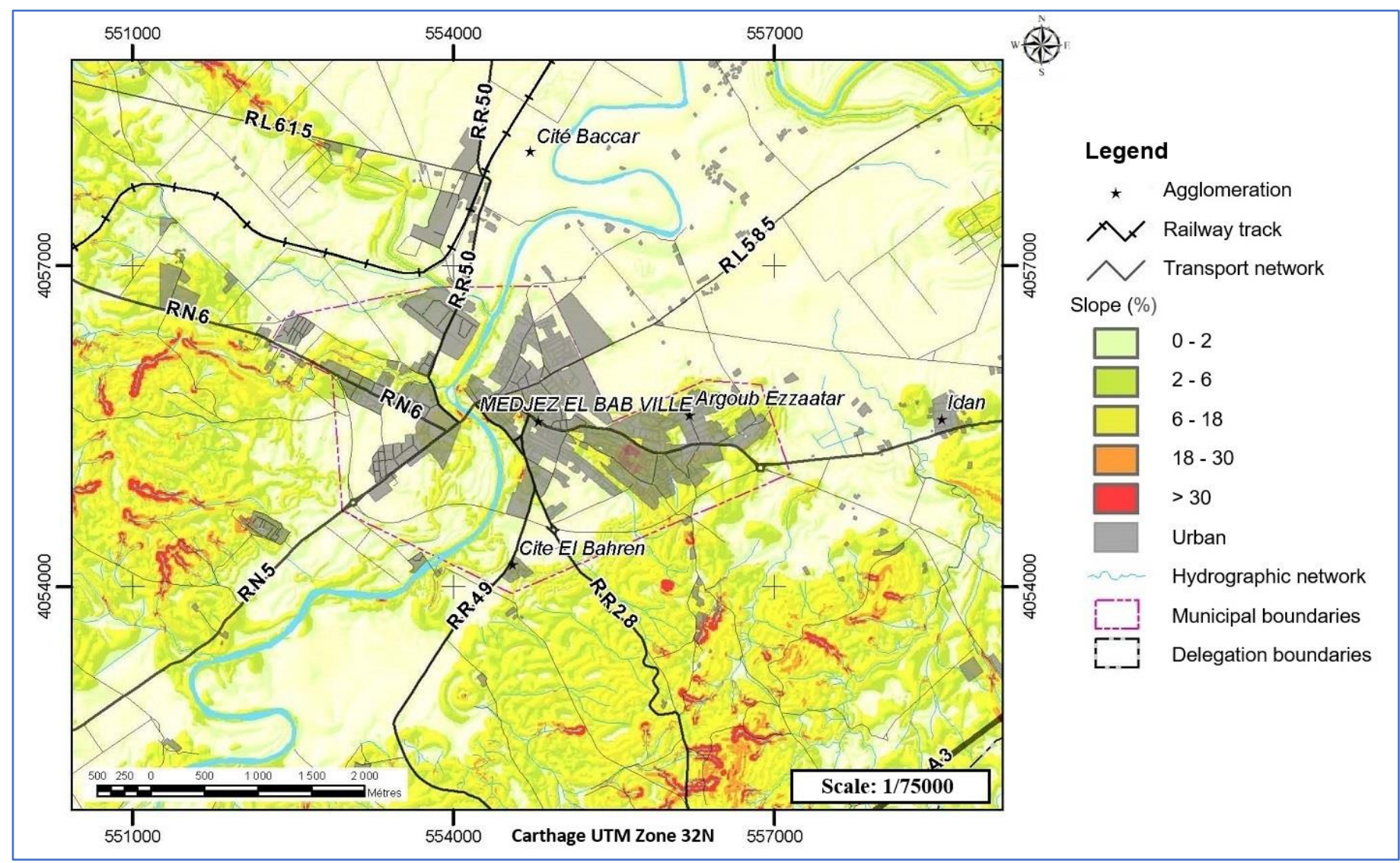

Figure 7. Slope map. 


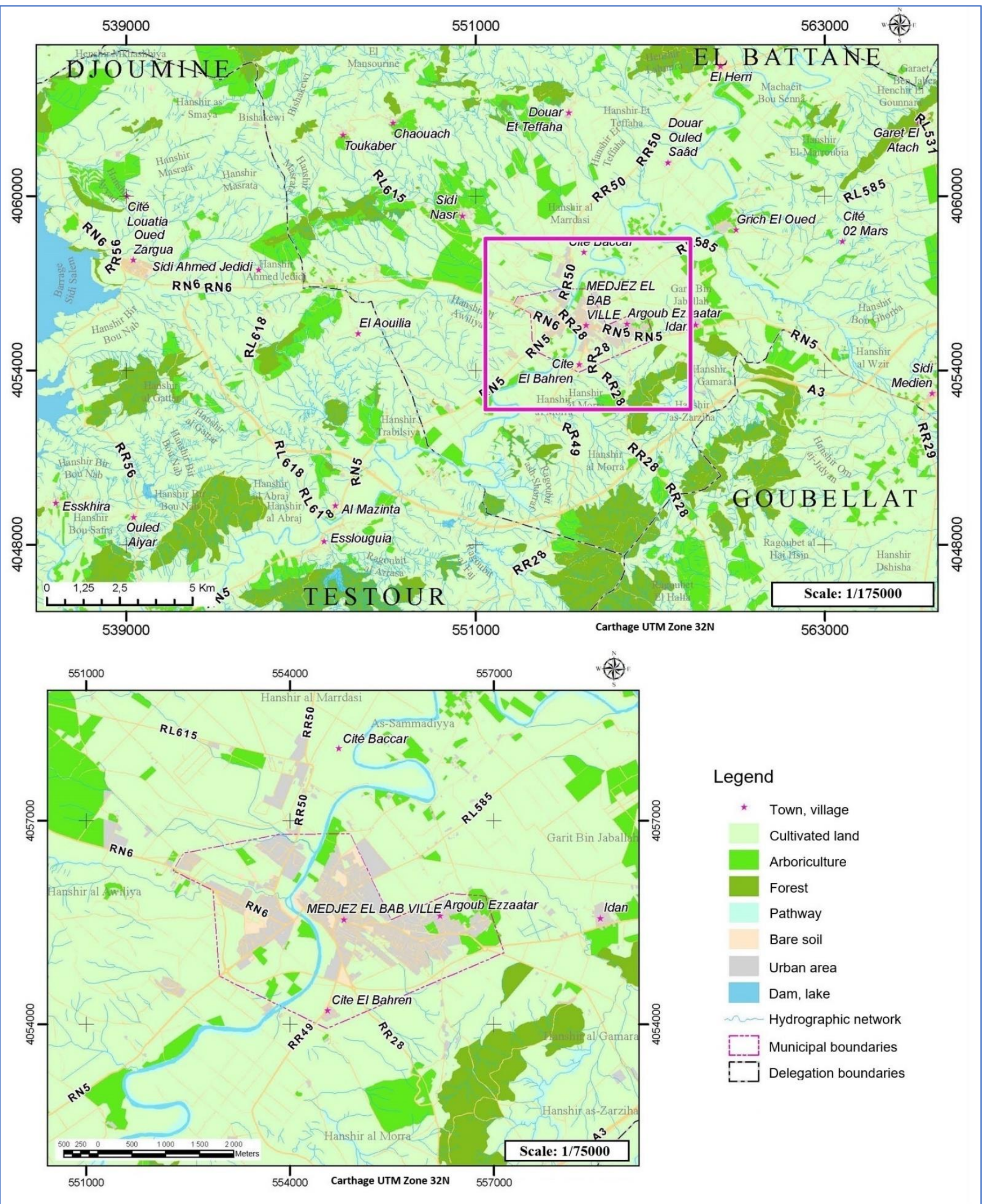

Figure 8. Land use map. 


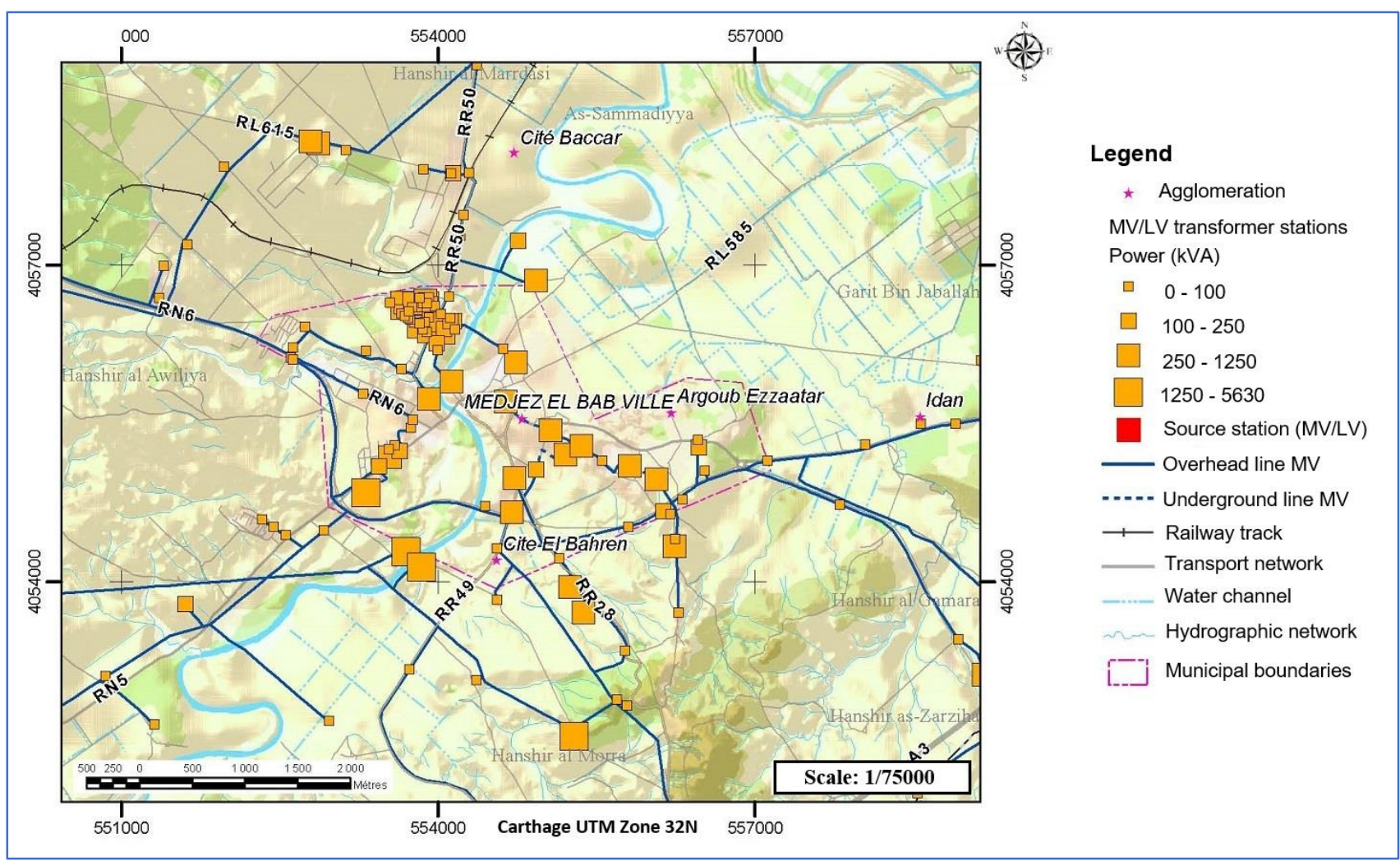

Figure 9. MV/LV transformer stations Power. 


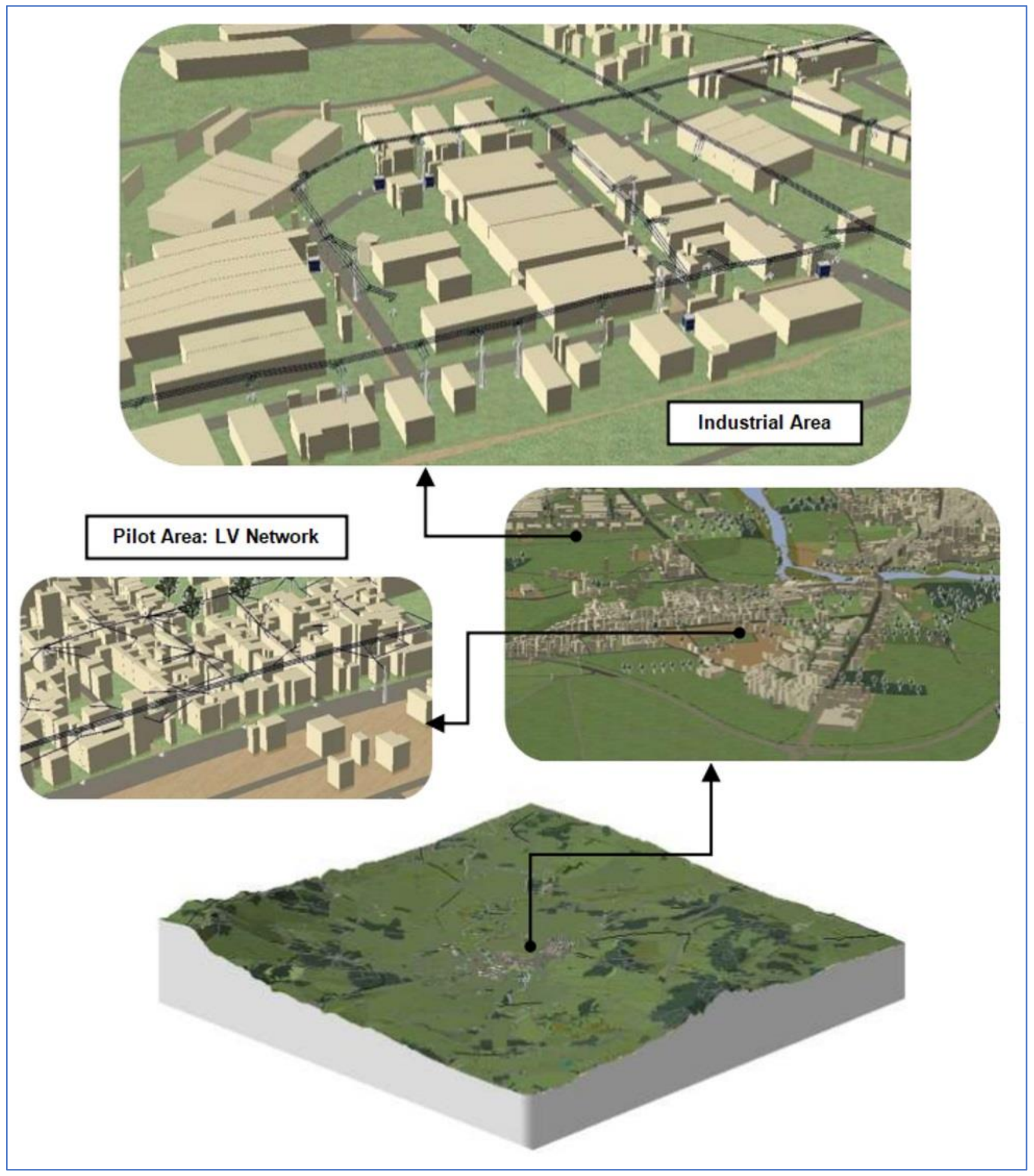

Figure 10. 3D model of the study area. 


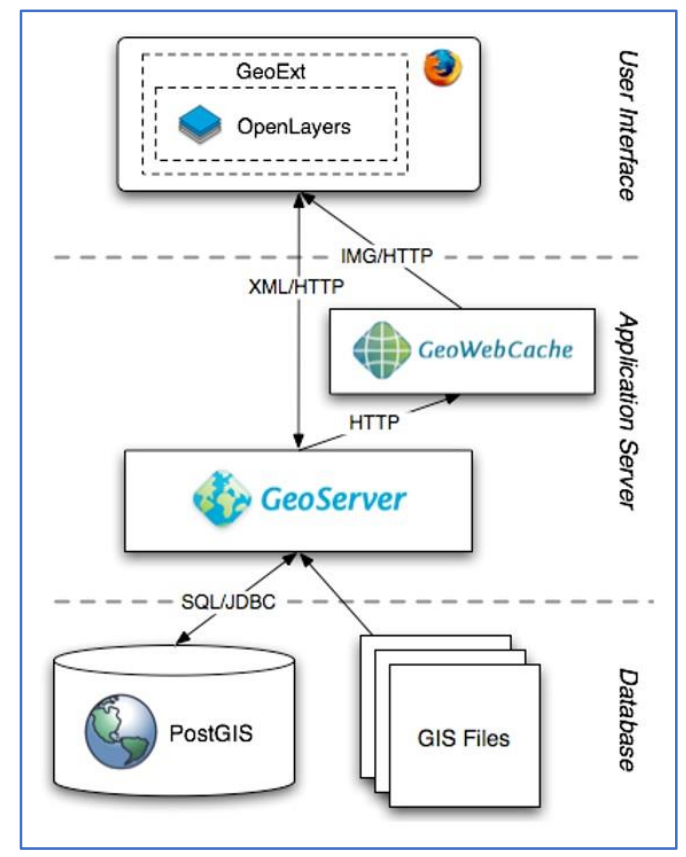

Figure 11. Structure of the Web GIS application.

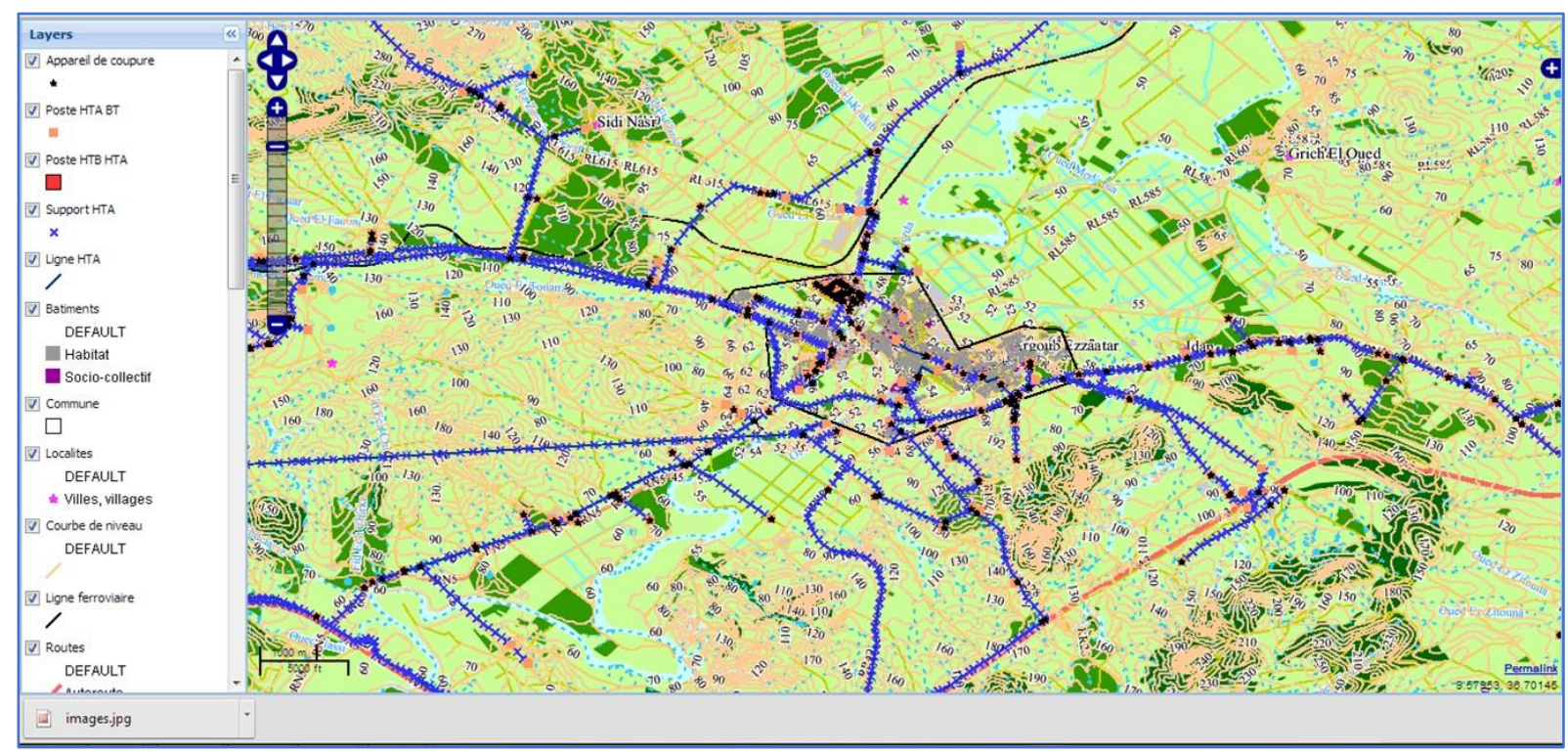

Figure 12. "Grand Medjez El Bab" cartographic interface. 


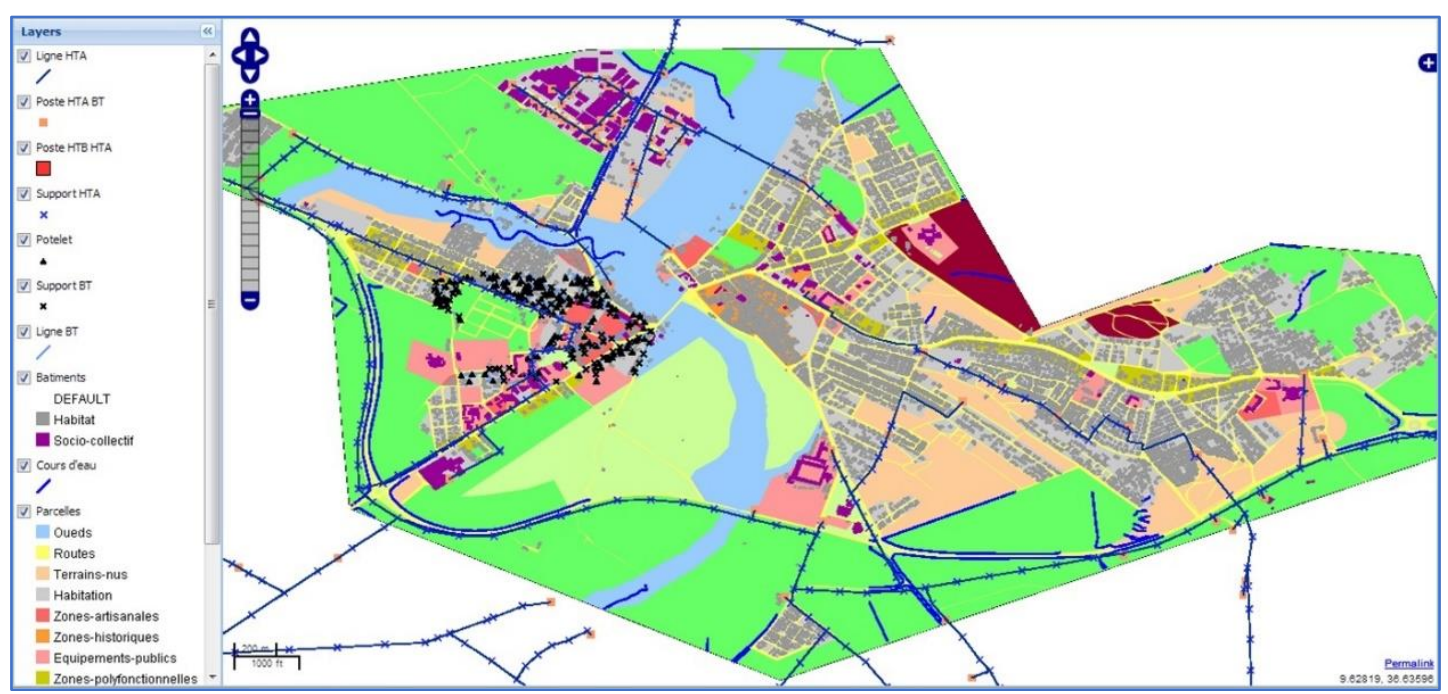

Figure 13. Medjez El Bab Municipality cartographic interface.

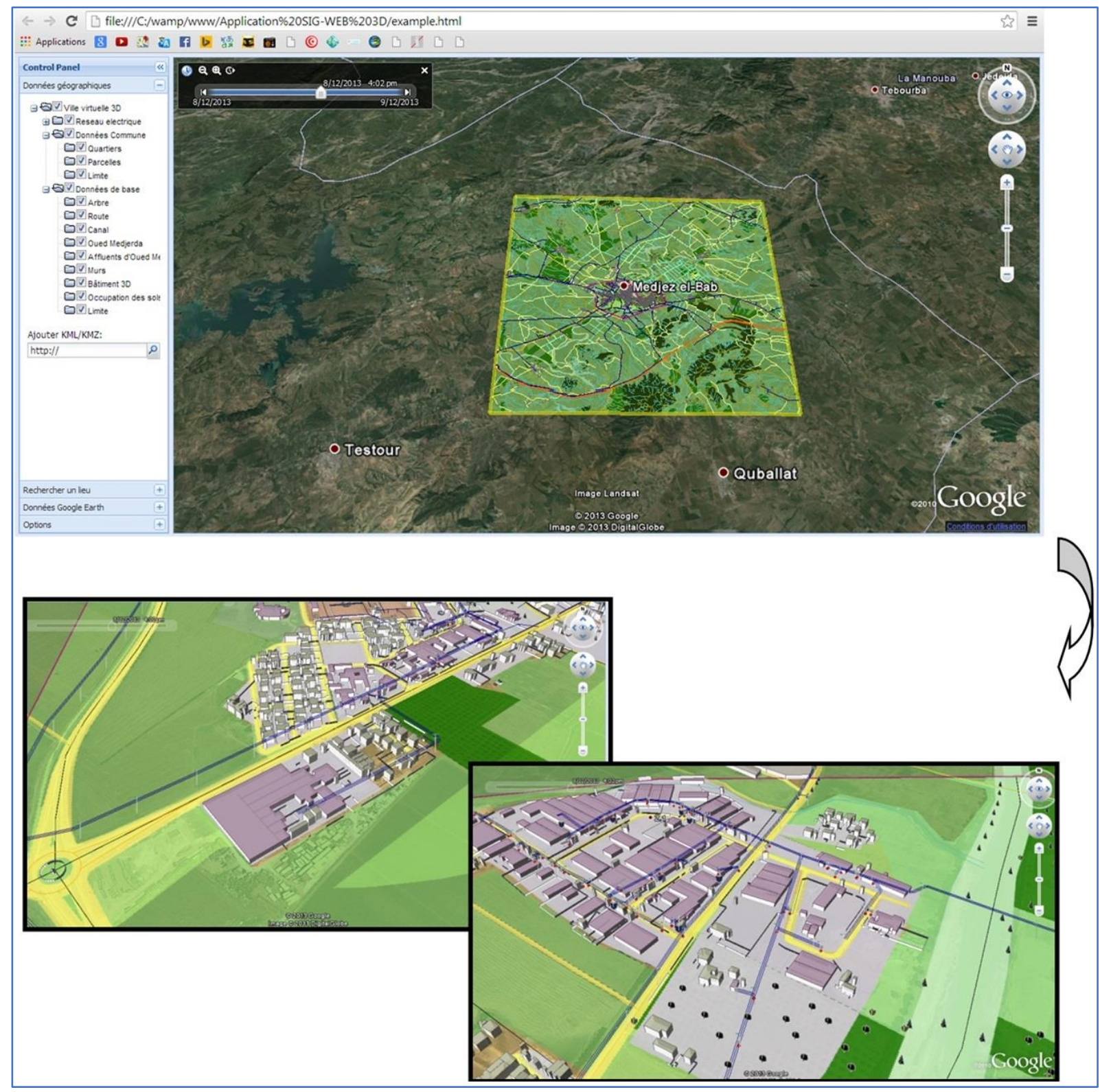

Figure 14. 3D cartographic interface. 


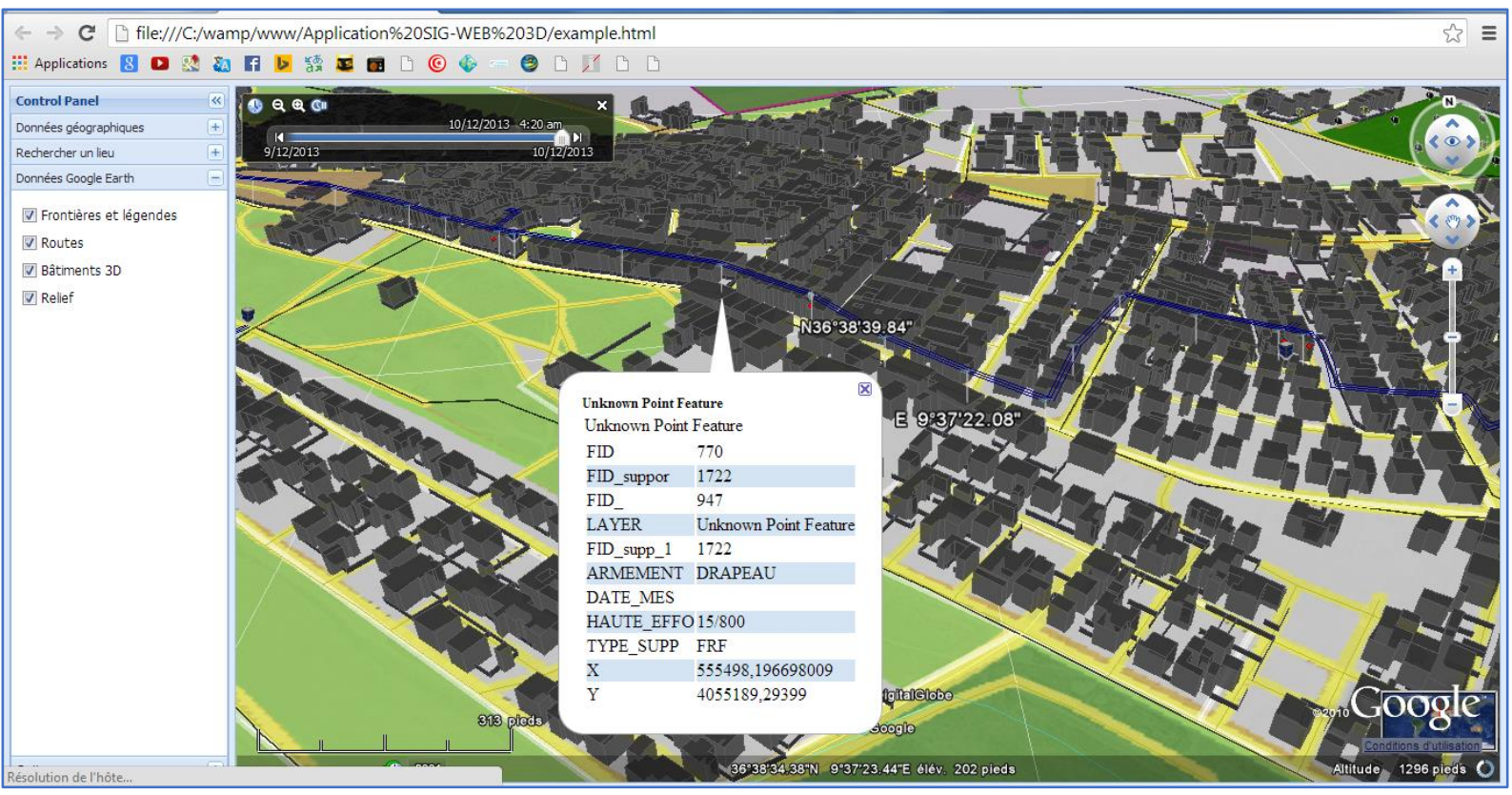

Figure 15. Display of Google Earth data and parameters (scale, planisphere, coordinates, etc.) for a selected object (MV line in that case).

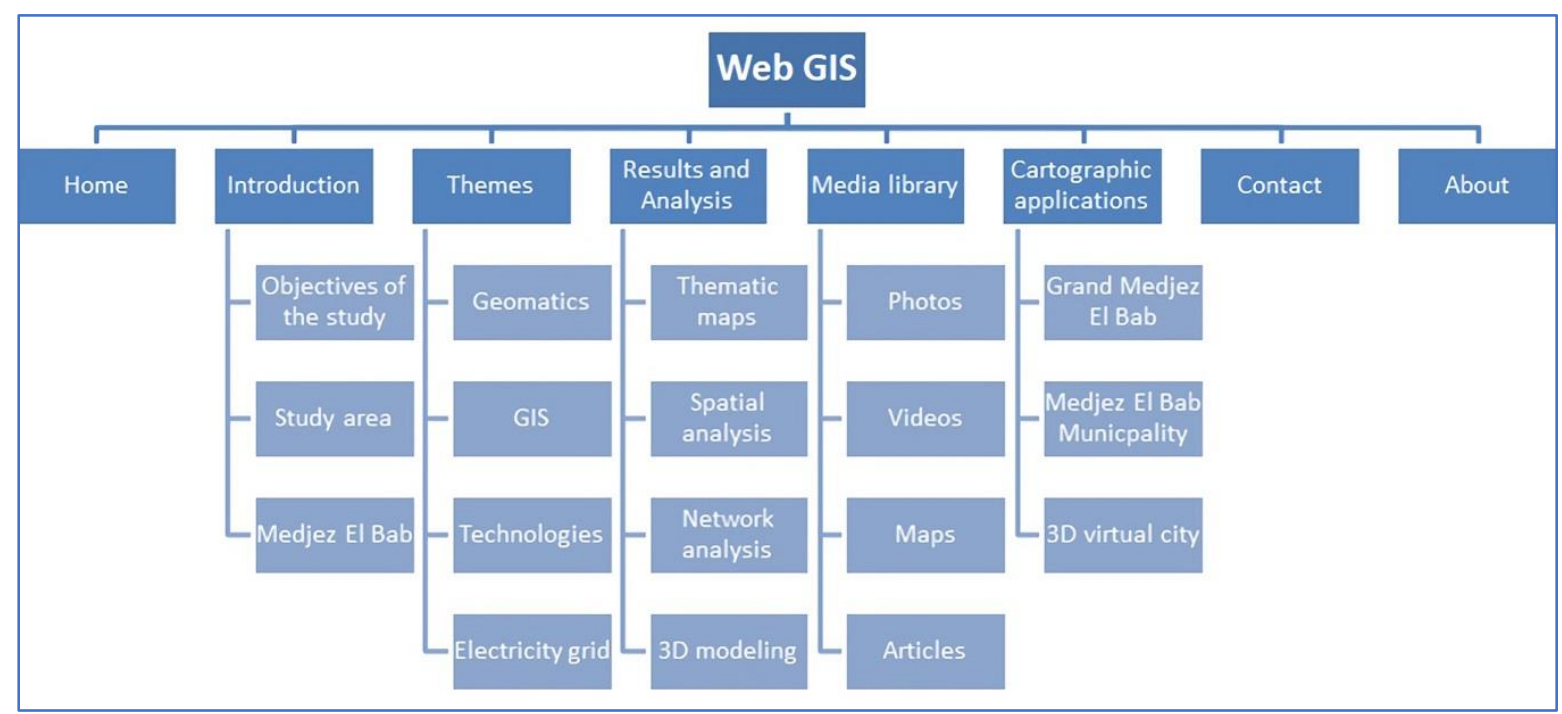

Figure 16. Website structuring. 


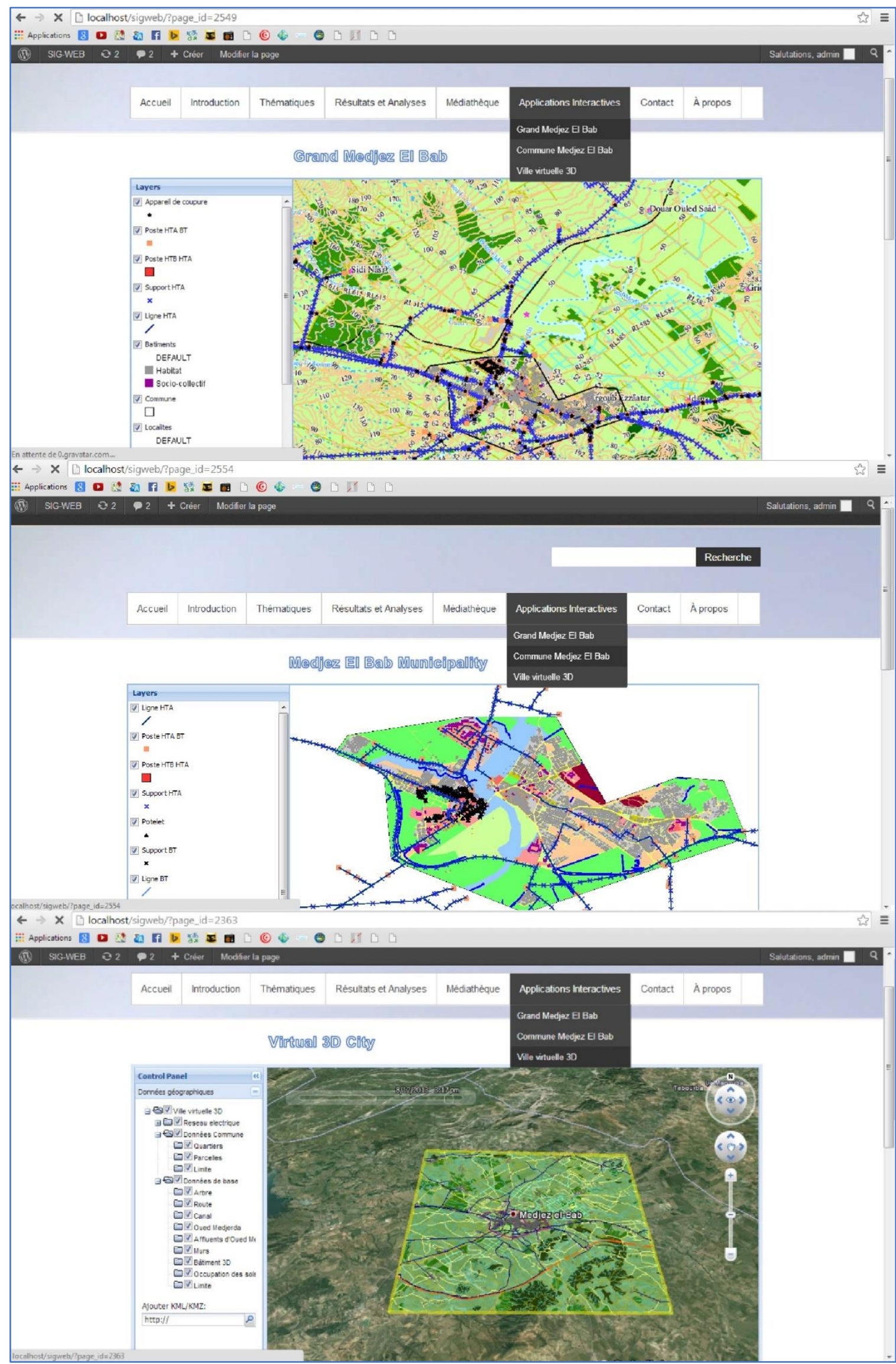

Figure 17. Interactive applications "Grand Medjez El Bab", "Medjez El Bab Municipality" and "3D virtual city". 


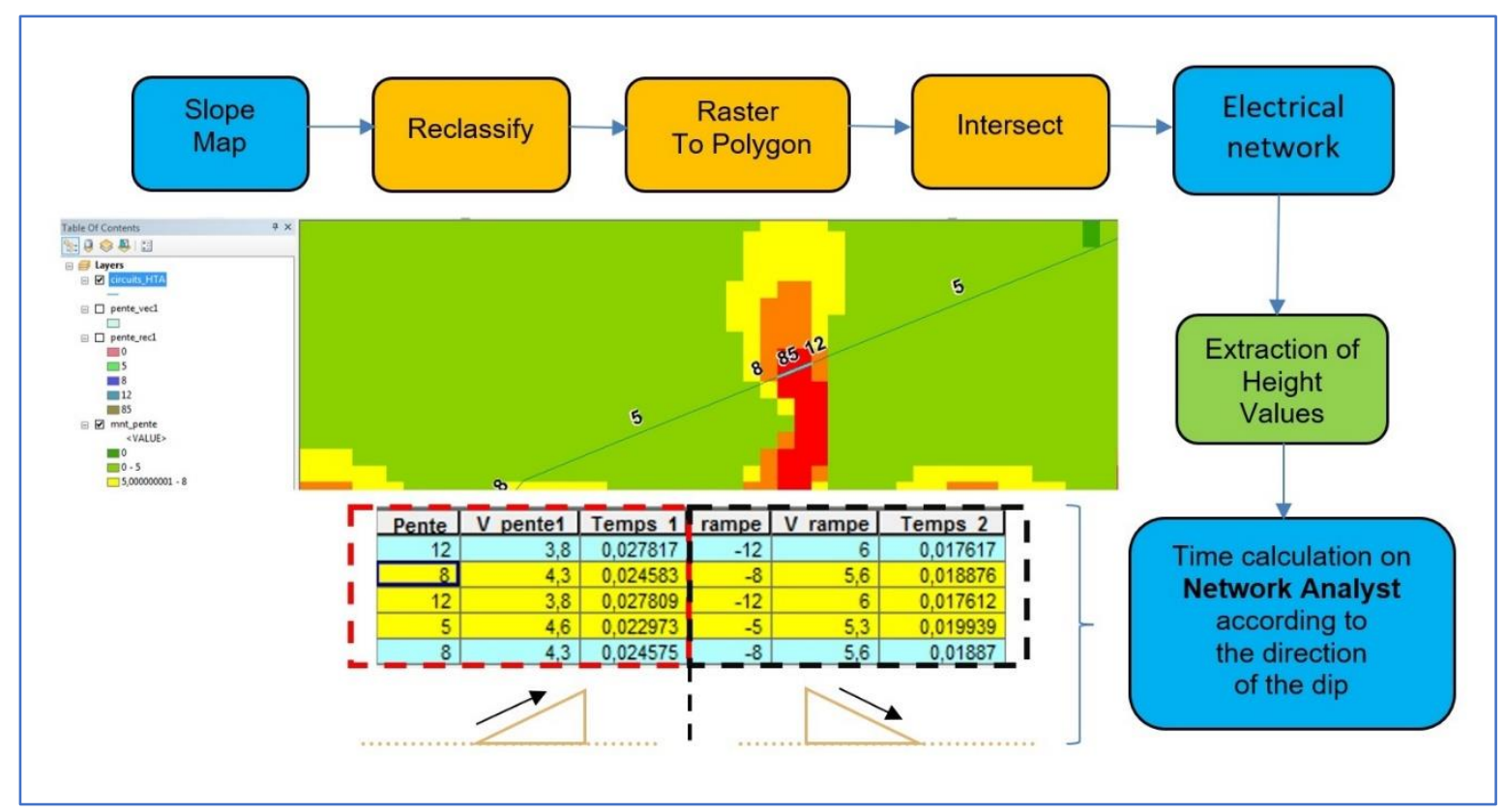

Figure 18. Workflow showing the intersection of slope map with the electrical network and speed and time calculation according to slope value and direction
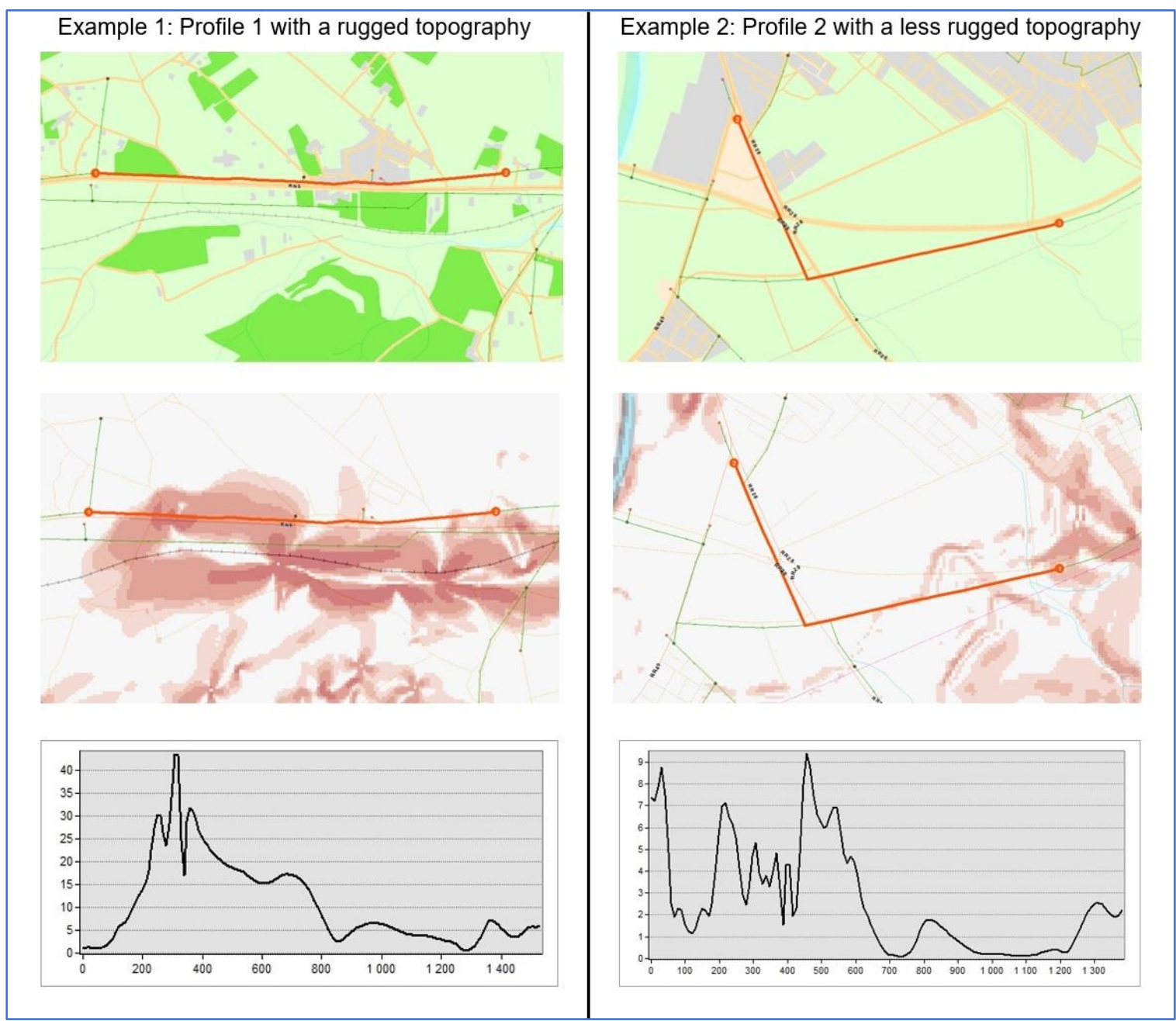

Figure 19. The two profiles used as examples to show the variation of time and speed according to slope. 


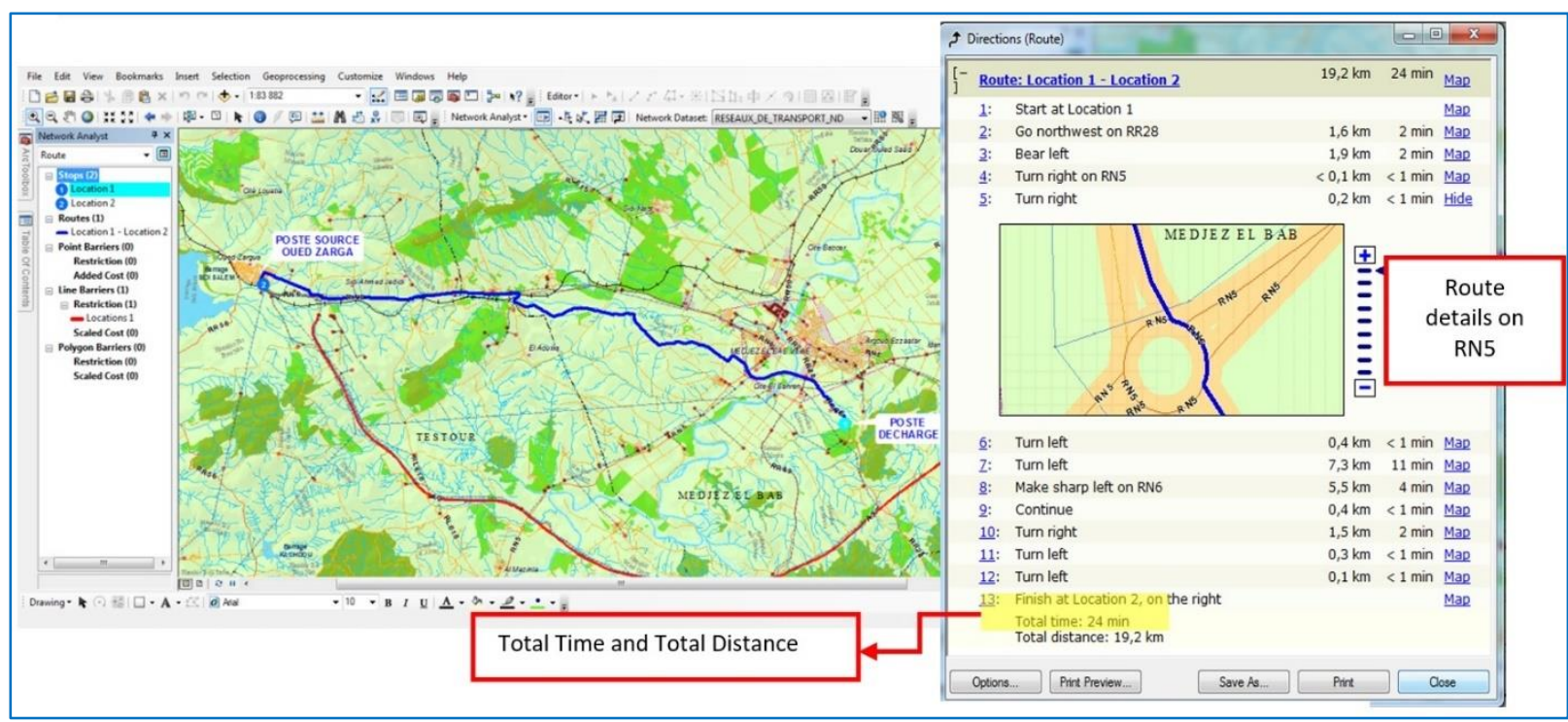

Figure 20. Analysis result of the shortest path between the "Oued Zarga" source station and the transformer station



Figure 21. Polygons representing service areas of 5, 10, 15, 20 and 30 minutes from Medjez El Bab City (ArcGIS Network Analyst application)

\section{References}

[1] Gonen T (2014) Electrical Power Transmission System Engineering, Analysis and Design, CRC Press, New York, Taylor and Francis

[2] Wei W, Liu, F, Mei S (2016) Charging strategies of EV aggregator under renewable generation and congestion: a normalized nash equilibrium approach. IEEE Trans. Smart Grid, 7 (3), pp. 1630-1641 https://doi.org/10.1109/TSG.2015.2477844

[3] Luo, Z, Hu Z, Song Y, Xu, Z, Lu H (2013) Optimal coordination of plug-in electric vehicles in power grids with cost-benefit analysis - Part II: A case study in China. IEEE Transactions on Power Systems, 28(4), 3556-3565 https://doi.org/10.1109/TPWRS.2013.2252028

[4] Mejía-Alzate ML (2018) Análisis Interorganizacional en la Gobernanza Turística de la Ciudad de , Colombia. Revista LatinoAmericana de Turismologia. 4, 2, 8-22 https://doi.org/10.34019/2448-198X.2018.v4.13942 
[5] Câmara AMM, Gilberto SDF, Marília SC (2004) Spatial Analysis and GIS: A Primer, Image Processing Division, National Institute for Space Research (INPE), Av dos Astronautas 1758, São José dos Campos, Brazil Brazilian Agricultural Research Agency (EMBRAPA), Rodovia Brasília-Fortaleza, BR 020, Km 18, Planaltina, Brazil National School for Public Health, Fundacao Oswaldo Cruz R. Leopoldo Bulhoes, 1480/810, Rio de Janeiro, Brazil

[6] Duckham M, Goodchild MF, Worboys MF (2003) Fundamentals of Geographic Information Science. New York, Taylor and Francis

[7] Goodchild MF (1992) Geographical information science. International Journal of Geographical Information Systems 6(1): 31-45 https://doi.org/10.1080/02693799208901893

[8] Hamza MH, Added A, Rodriguez R, Abdeljaoued S, Ben Mammou A (2007) A GIS-based DRASTIC vulnerability and net recharge reassessment in an aquifer of a semi-arid region (Metline-Ras Jebel-Raf Rafaquifer, Northern Tunisia). Jour. Environ. Managmt., v.84, pp.12-19, Elsevier https://doi.org/10.1016/j.jenvman.2006.04.004

[9] Gutiérrez Pueblo J, Gould M (1994) SIG: Sistemas de información Geográfica, Madrid, Síntesis

[10] Steede-Terry K (2000) Integrating GIS and the Global Positioning System, ESRI, Redlands, CA

[11] Goodchild MF, Haining RP (2004) GIS and spatial data analysis: Converging perspectives. In: Florax R.J.G.M., Plane D.A. (eds) Fifty Years of Regional Science. Advances in Spatial Science. Springer, Berlin, Heidelberg https://doi.org/10.1007/978-3-662$\underline{07223-316}$

[12] Mejia Alzate MA, Melo Trujillo JD, Zambrano-Asanza S, Padilha-Feltri A (2020) Spatial-temporal growth model to estimate the adoption of new end-use electric technologies encouraged by energy-efficiency programs, Energy, vol. 191(C), Elsevier https://doi.org/10.1016/j.energy.2019.116531

[13] Mejia Alzate MA, Melo Trujillo JD, Padilha Feltrin A, Sánchez Zuleta CC, Fernández Gutiérrez JP (2018) Geographical information systems as a Tool to assist the electricity distribution Networks planning. Revista EIA, 15(29), 71-85 http://doi.org/10.24050/reia.v15i29.1138

[14] Nawaz-ul-Huda S, Burke F, Azam M, Naz S (2012) GIS for power distribution network: A case study of Karachi, Pakistan, GEOGRAFIA, Malaysia Journal of Society and Space, 8 issue 1, 60-68, ISSN 2180-2491

[15] Kaijuka E (2007) GIS and rural electricity planning in Uganda, Journal of Cleaner Production, Volume 15, Issue 2, 203-217, Elsevier https://doi.org/10.1016/j.jclepro.2005.11.057

[16] Putz S (1994) Interactive information services using World Wide Web HyperText[R]. Prepared for the first International Conference on World Wide Web, May 25- 27, 1994, Geneva, Switzerland

[17] Longley PA, Goodchild MF, Maguire DJ, Rhind DW (2005) Geographic information systems and science. Second Edition, Wiley, Chichester. ISBN 047087001 X. $197 \cdot 260 \mathrm{~mm}$. xvii +517 pages

[18] Datta A, Mohanty P (2013) Enterprise GIS and Smart Electric Grid for India's power sector, IEEE PES Innovative Smart Grid Technologies Conference (ISGT), Washington, DC, , pp. 1-7 https://doi.org/10.1109/ISGT.2013.6497806

[19] Chmit M (2014) Conception et réalisation d'une application SIG-WEB pour l'analyse et la gestion des réseaux électriques HTA/BT de la ville de Medjez El Bab. Mémoire de Mastère Professionnel en Géomatique, Terre et Aménagement, Section de Géomatique, Département de Géologie, Faculté des Sciences de Tunis+Geocarte, Mémoire encadré par Hamza MH

[20] Zheng FM, Ma L, Liu N, Chen J (2012) "Assessment for Distribution Network Planning Schemes of Urban Electric Power System." Energy Procedia 14, Elsevier, pp. 1067-74 http://dx.doi.org/10.1016/j.egypro.2011.12.1056

[21] Mentis D, Welsch M, Fuso Nerini F, Broad O, Howells M, Bazilian M, Rogner H (2015) A GIS-based approach for electrification planning-A case study on Nigeria. Energy for Sustainable Development, Elsevier, vol. 29, pp. 142-150 https://doi.org/10.1016/j.esd.2015.09.007

[22] Candelise C, Westacott P (2017) Can integration of PV within UK electricity network be improved? A GIS based assessment of storage, Energy Policy, Elsevier, vol. 109(C), pp. 694-703 https://doi.org/10.1016/j.enpol.2017.07.054

[23] Ashkezari A D , Hosseinzadeh N, Chebli A, Albadi M (2018) Development of an enterprise Geographic Information System (GIS) integrated with smart grid, Sustainable Energy, Grids and Networks, Elsevier, vol. 14, pp. 25-34 https://doi.org/10.1016/j.segan.2018.02.001

[24] Li M, Lenzen M, Wang D, Nansai K (2020) GIS-based modelling of electric-vehicle-grid integration in a $100 \%$ renewable electricity grid," Applied Energy, Elsevier, vol. 262(C) https://doi.org/10.1016/j.apenergy.2020.114577

[25] Taye B, Workineh T, Nebey A, Kefale H A (2020) Rural electrification planning using Geographic Information System (GIS), Cogent Engineering, Taylor and Francis, Volume 7- Issue 1 https://doi.org/10.1080/23311916.2020.1836730

[26] Office de la Topographie et du Cadastre OTC (1982 to 1988) Topographic Maps 1/25000: Beja S.E (Feuille N 18), Tebourba S.E (Feuille $\left.\mathrm{N}^{\circ} 19\right)$, Tebourba S.O (Feuille $\mathrm{N}^{\circ} 19$ ), Oued Ezzarga (Feuille $\mathrm{N}^{\circ} 26$ ), Oued Ezzarga (Feuille $\left.\mathrm{N}^{\circ} 26\right), \mathrm{Mjaz}^{\circ}$ al Bab NE (Feuille $\mathrm{N}^{\circ} 27$ ), Mjaz al Bab NO (Feuille $\mathrm{N}^{\circ} 27$ ), Mjaz al Bab SE (Feuille N²7), Mjaz al Bab SO (Feuille $\mathrm{N}^{\circ} 27$ )

[27] Ben Lassoued T (2006) Topographic plans of Medjez El Bab, scale 1:1000

[28] Maxar Technologies (2019) Maxar Technologies Awarded Four-Year Global EGD Contract by the U.S. Government for On Demand Access to Mission-Ready Satellite Imagery. Sensor and Systems, August 28

[29] Rochfeld A, Tardieu H (1983) MERISE: An information system design and development methodology https://doi.org/10.1016/0378-7206(83)90032-0

[30] Avison D (1991) MERISE: A European Methodology for Developing Information Systems, European Journal of Information Systems, Jan. 1991, p. 183-191 https://doi.org/10.1057/ejis.1991.33

[31] Sherman R. (2015) Business Intelligence Guidebook From Data Integration to Analytics, Chapter 8: Foundational Data Modeling, edited by MK, Pages 173-195 
[32] ESRI (2007) ESRI ArcGIS Diagrammer User Guide

[33] Perkal J (1965) Proba obiektywnej generalizacji, Geodezja i Karografia, VII:2, pp.130-142 (1958) English translation, "An Attempt at Objective Generalization" Discussion Papers of The Michigan Inter-university Community of Mathematical Geographers

[34] Tobler WR (1966) Numerical map generalization: And, Notes on the analysis of geographical distributions (Discussion paper Michigan Inter-University Community of Mathematical Geographers) [30] Töpfer, F., Pillewizer, W. The Principles of Selection, The Cartographic Journal, 3:1, 10-16 (1966) https://doi.org/10.1179/caj.1966.3.1.10

[35] Nyangweso D (2013) Cartographic Generalization in Multi-scale Environment: Case study of Lamu County, Kenya, International Journal of Science and Research (IJSR) 5(9):804-813 https://doi.org/10.21275/ART20161673

[36] Hutchinson MF (1988) Calculation of hydrologically sound digital elevation models. Paper presented at Third International Symposium on Spatial Data Handling at Sydney, Australia

[37] Hutchinson MF (1989) A new procedure for gridding elevation and stream line data with automatic removal of spurious pits. Journal of Hydrology 106: 211-232 https://doi.org/10.1007/s10110-003-0190-y

[38] Singh SP, Jain K, Mandla VR (2013) Virtual 3D city modeling: Techniques and applications, Int. Arch. Photogramm. Remote Sens. Spatial Inf. Sci., XL-2/W2, 73-91 https://doi.org/10.5194/isprsarchives-XL-2-W2-73-2013

[39] Biljecki F, Ledoux H, Stoter J, Vosselman G (2016) The variants of an LOD of a 3D building model and their influence on spatial analyses. ISPRS Journal of Photogrammetry and Remote Sensing, vol. 116, pp. 42-54, Elsevier https://doi.org/10.1016/j.isprsjprs.2016.03.003

[40] Mignard C, Nicolle C (2014) Merging BIM and GIS using ontologies application to urban facility management in ACTIVe3D. Computers in Industry. 65(9):1276-1290, Elsevier https://doi.org/10.1016/j.compind.2014.07.008

[41] Tekdal-Emniyeti E, Haefele K, Isele J, Celik RN (2011) 3D documentation of historical sites and buildings for interdisciplinary works, Proc. SPIE 8085, Videometrics, Range Imaging, and Applications XI, 80850V https://doi.org/10.1117/12.889516

[42] Internet World Stats (2020) Usage and Population Statistics http://www.internetworldstats.com/stats.htm

[43] Auer M, Zipf A (2018) 3D WebGIS: From Visualization to Analysis. An Efficient Browser-Based 3D Line-of-Sight Analysis. ISPRS Int. J. Geo-Inf. 7, 279 https://doi.org/10.3390/ijgi7070279

[44] Siddiqueea M Z H , Strzalkab A, Eicker U (2009) Publication of energy consumption data of Scharnhauser park via Web GIS, Applied Geoinformatics for Society and Environment conference, Volume 103, Publications of the Stuttgart University of Applied Sciences Hochschule für Technik Stuttgart, Franz-Josef Behr, Dietrich Schröder, Anakkathil Purushothaman Pradeepkumar (Editors)

[45] Fu P, Sun J (2011) Web GIS: Principles and Applications; ESRI Press: Redlands, CA, USA, ISBN 9781589482456

[46] ESRI (2016) Web GIS, Simply

[47] Khan ZA, Adnan M (2010) Usability Evaluation of Web-based GIS Applications, A Comparative Study of Google Maps and MapQuest, Master Thesis Computer Science, School of Computing, Blekinge Institute of Technology, Ronneby, Sweden

[48] Mwangi EK, Kimani S, Mindila A (2017) A Review Of Web-based Gis Usability Elements, Researchjournali's Journal Of Information Technology

[49] Von Schwerin J, Richards-Rissetto H, Remondino F, Agugiaro G, Girardi G (2013) The MayaArch3D project: A 3D WebGIS for analyzing ancient architecture and landscapes, Literary and Linguistic Computing, Volume 28, Issue 4, Pages 736-753 https://doi.org/10.1093/llc/fqt059

[50] Haklay M, Zafiri A (2008) Usability Engineering for GIS: Learning from a Screenshot. The Cartographic Journal, XLV(2), pp. 8796, Taylor \& Francis https://doi.org/10.1179/174327708X305085

[51] Newman G, Zimmerman D, Crall A, Laituri M, Graham J, Stapel L (2010) User-friendly web mapping: lessons from a citizen science website, International Journal of Geographical Information Science, 24:12, 1851-1869, Taylor E Francis https://doi.org/10.1080/13658816.2010.490532

[52] Hagedorn B (2010) Web View Service Discussion Paper. OGC Discussion Paper, Ref. No. OGC 09-166r2; Open Geospatial Consortium http://portal.opengeospatial.org/files/?artifact id=37257

[53] Schilling A, Kolbe TH (2010) Draft for Candidate OpenGIS(R) Web 3D Service Interface Standard. OGC Discussion Paper, Ref. No. OGC 09-104r1; Open Geospatial Consortium http://portal.opengeospatial.org/files/?artifact id=36390

[54] Hagedorn B, Thum S, Reitz T, Coors V, Gutbell R (2017) OGC® 3D Portrayal Service 1.0. OGC Implementation Standard, Ref. No. OGC 15-001r4; Open Geospatial Consortium http://docs.opengeospatial.org/is/15-001r4/15-001r4.html

[55] Coors V, Zipf A (Eds.) (2005) 3D-Geo information system. Grundlagen und Anwendungen; Wichmann: Heidelberg, Germany; pp. XXII, 522

[56] Abdul-Rahman A, Pilouk M (2008) Spatial Data Modelling for 3D GIS; Springer: Berlin/Heidelberg, Germany, pp. 1-289

[57] Victor N (2010) Modélisation de l'accessibilité piétonne à Luxembourg-Ville, Rapport de Stage, CEPS/INSTEAD, Master SIG et Gestion de l'Espace, Université Jean Monnet, Saint-Etienne, 54 p. (+ annexes et livret cartographique).

\section{Declarations}

Funding: no

Conflicts of interest/Competing interests: no 